\title{
Location and Function of the Slow Afterhyperpolarization Channels in the Basolateral Amygdala
}

\author{
John M. Power, Christina Bocklisch, Peter Curby, and Pankaj Sah \\ The Queensland Brain Institute, The University of Queensland, Brisbane, Queensland, 4072, Australia
}

The basolateral amygdala (BLA) assigns emotional significance to sensory stimuli. This association results in a change in the output (action potentials) of BLA projection neurons in response to the stimulus. Neuronal output is controlled by the intrinsic excitability of the neuron. A major determinant of intrinsic excitability in these neurons is the slow afterhyperpolarization (sAHP) that follows action potential (AP) trains and produces spike-frequency adaptation. The sAHP is mediated by a slow calcium-activated potassium current $\left(s I_{\mathrm{AHP}}\right)$, but little is known about the channels that underlie this current. Here, using whole-cell patch-clamp recordings and high-speed calcium imaging from rat BLA projection neurons, we examined the location and function of these channels. We determined the location of the $s I_{\mathrm{AHP}}$ by applying a hyperpolarizing voltage step during the $s I_{\mathrm{AHP}}$ and measuring the time needed for the current to adapt to the new command potential, a function of its electrotonic distance from the somatic recording electrode. Channel location was also probed by focally uncaging calcium using a UV laser. Both methodologies indicated that, in BLA neurons, the $s I_{\mathrm{AHP}}$ is primarily located in the dendritic tree. EPSPs recorded at the soma were smaller, decayed faster, and showed less summation during the sAHP. Adrenergic stimulation and buffering calcium reduced the sAHP and the attenuation of the EPSP during the sAHP. The sAHP also modulated the AP in the dendrite, reducing the calcium response evoked by a single AP. Thus, in addition to mediating spike-frequency adaptation, the $s I_{\mathrm{AHP}}$ modulates communication between the soma and the dendrite.

\section{Introduction}

Neurons in the basolateral amygdala (BLA) are believed to be involved in assigning affective value to sensory stimuli. This association results in a change in the output [action potentials (APs)] of BLA projection neurons in response to the sensory stimulus. The output of neurons, in both the BLA and elsewhere, is determined by the synaptic inputs they receive, as well as their intrinsic excitability. Projection neurons will often fire bursts of APs both spontaneously (Paré and Gaudreau, 1996) and in response to complex sensory stimuli that have emotional significance (O'Keefe and Bouma, 1969; Nishijo et al., 1988). After a burst of APs, most BLA projection neurons show a prolonged afterhyperpolarization, lasting several seconds (Womble and Moises, 1993). This slow afterhyperpolarization (sAHP) causes spike-frequency adaptation and is a major determinant of intrinsic excitability (Madison and Nicoll, 1982). In BLA projection neurons, the sAHP is primarily mediated by the calciumactivated potassium current $s I_{\mathrm{AHP}}$ (Womble and Moises, 1993; Power and Sah, 2008). The $s I_{\mathrm{AHP}}$ is modulated by a number of neuromodulators, including acetylcholine, noradrenaline (NA),

Received Feb. 28, 2010; revised 0ct. 25, 2010; accepted 0ct. 27, 2010.

This work was supported by grants from the National Health and Medical Research Council. J.M.P. is supported by a Smart State Fellowship funded by the Queensland State Government and Carl Zeiss Australia. We thank Rowan Tweedale for her comments on this manuscript.

C. Bocklisch's present address: Departement des Neurosciences Fondamentales, Centre Médical Universitaire 1, rue Michel Servet, 1211 Genève 4, Switzerland.

Correspondence should be addressed to John Power or Pankaj Sah, Queensland Brain Institute, The University of Queensland, Brisbane, QLD 4072, Australia. E-mail: john.power@uq.edu.au, pankaj.sah@uq.edu.au.

DOI:10.1523/JNEUROSCI.1045-10.2011

Copyright $\odot 2011$ the authors $\quad 0270-6474 / 11 / 310526-12 \$ 15.00 / 0$ and glutamate, that act via G-protein-coupled receptors to suppress the $s I_{\mathrm{AHP}}$ and block spike-frequency adaptation (Nicoll, 1988; Womble and Moises, 1993, 1994; Huang et al., 1996; Power and Sah, 2008).

Although the $s I_{\mathrm{AHP}}$ has an established role in determining the intrinsic excitability of BLA projection neurons, little is known about the underlying channels. Studies in hippocampal pyramidal neurons have indicated that both SK (Lima and Marrion, 2007) and KCNQ (Tzingounis and Nicoll, 2008; Tzingounis et al., 2010) potassium channels, which mediate $I_{\mathrm{AHP}}$ and $I_{\mathrm{M}}$, respectively (Hille, 2001), also contribute to the $s \mathrm{AHP} / s I_{\mathrm{AHP}}$. However, specific blockers of SK and KCNQ channels have only a minor impact on the sAHP in BLA projection neurons (Womble and Moises, 1993; Power and Sah, 2008), and their molecular identity remains a mystery. Additionally, the subcellular distribution of the channels underlying the $\mathrm{sAHP} / \mathrm{s} I_{\mathrm{AHP}}$ has not been examined in these neurons. In hippocampal pyramidal neurons, in which they have been studied extensively, their location remains controversial. Some studies have placed these channels on the soma (Lima and Marrion, 2007), whereas other reports suggest that they are localized on the dendritic tree (Andreasen and Lambert, 1995; Sah and Bekkers, 1996; Bekkers, 2000). A dendritic location suggests that the role of the $s I_{\mathrm{AHP}}$ is not restricted to spike-frequency adaptation but that it may also be involved in shaping synaptic potentials. Indeed, in hippocampal pyramidal neurons, EPSP kinetics and their temporal summation are altered during the sAHP (Sah and Bekkers, 1996; Lancaster et al., 2001; Fernández de Sevilla et al., 2007). Here we show that, in BLA projection neurons, the channels underlying the $s I_{\mathrm{AHP}}$ are primarily located in the dendritic tree. Activation of these chan- 
nels not only shapes the EPSP and synaptic summation but also modulates the AP-evoked calcium response in the dendrite.

\section{Materials and Methods}

Slice preparation. Coronal brain slices $(300-350 \mu \mathrm{m})$ were prepared using standard techniques (Power and Sah, 2002). Twenty-one- to 28-dold Wistar rats were anesthetized with halothane and decapitated. Slices were prepared using a vibrating microslicer (DTK-1000; Dosaka EM). These procedures were conducted in accordance with the guidelines of the University of Queensland Animal Ethics Committee. Slices were incubated at $33^{\circ} \mathrm{C}$ for $30 \mathrm{~min}$ and then maintained at room temperature in artificial CSF (ACSF) solution containing the following (in mM): 119 $\mathrm{NaCl}, 2.5 \mathrm{KCl}, 1.3 \mathrm{MgCl}_{2}, 2.5 \mathrm{CaCl}_{2}, 1.0 \mathrm{Na}_{2} \mathrm{H}_{2} \mathrm{PO}_{4}, 26.2 \mathrm{NaHCO}_{3}$, and 11 glucose (equilibrated with $95 \% \mathrm{O}_{2}, 5 \% \mathrm{CO}_{2}$ ).

Electrophysiology. Slices were perfused with ACSF heated to $33^{\circ} \mathrm{C}$, and whole-cell patch-clamp recordings were made from the soma of BLA neurons using infrared differential interference contrast video microscopy. Patch pipettes (2-5 $\mathrm{M} \Omega$ ) were filled with an internal solution containing the following (in $\mathrm{mm}$ ): $135 \mathrm{KMeSO}_{4}, 8 \mathrm{NaCl}, 10$ HEPES, $2 \mathrm{Mg}_{2}$-ATP, $0.3 \mathrm{Na}_{3}$-GTP, 0.1 spermine, and 0.3 EGTA, pH 7.3 with $\mathrm{KOH}$ (osmolarity, 280-290 mOsm). In some experiments, fluorescent dyes (Alexa Fluor 488 or Alexa Fluor 594) were added to the internal solution to visualize the dendritic tree. EGTA was omitted during calcium-imaging experiments.

Electrophysiological signals were amplified with either an Axopatch 1D or a Multiclamp 700A amplifier (Molecular Devices), filtered at 2-5 $\mathrm{kHz}$, digitized at $5-20 \mathrm{kHz}$ with an ITC-16 board (InstruTECH), and controlled using Axograph (AxoGraph Scientific). Whole-cell recordings were obtained from projection neurons in the basal nucleus of the BLA. Only cells that had resting potentials more negative than $-55 \mathrm{mV}$, AP amplitudes $>100 \mathrm{mV}$, and input resistances $>60 \mathrm{M} \Omega$ were included in the dataset. Projection neurons were distinguished from local circuit GABAergic based on their action potential waveform. Projection neurons have broader APs $(>0.7 \mathrm{~ms})$ and smaller fast AHPs $(<15 \mathrm{mV})$ than GABAergic neurons. Additionally projection neurons show frequencydependent spike broadening, which is absent in GABAergic neurons.

Voltage shift experiments. To enhance distal $\mathrm{GABA}_{\mathrm{A}}$ currents, we used a high $\mathrm{Cl}^{-}$internal solution containing the following (in $\mathrm{mM}$ ): $68 \mathrm{KCl}, 68$ $\mathrm{KMeSO}_{4}, 8 \mathrm{NaCl}, 10 \mathrm{HEPES}, 2 \mathrm{Mg}_{2}$-ATP, $0.3 \mathrm{Na}_{3}$-GTP, and 0.1 spermine. This resulted in a chloride reversal potential of $-14 \mathrm{mV}$. GABA (50 $\mu \mathrm{M}$ in ACSF) was applied by focal pressure application through a patch pipette using a picospritzer (10-30 psi, 50-500 ms; Parker Hannifin). To isolate $\mathrm{GABA}_{\mathrm{A}}$ currents, experiments were performed in the presence of the glutamate receptor antagonist kynurenic acid $(2 \mathrm{~mm})$ and the $\mathrm{GABA}_{\mathrm{B}}$ receptor antagonist CGP 55845 [(2S)-3-[(15)-1-(3,4-dichlorophenyl) ethyl] amino-2-hydroxypropyl)(phenylmethyl)phosphinic acid] (10 $\mu \mathrm{M})$. The $s I_{\mathrm{AHP}}$ voltage-shift time course was similar for high $\mathrm{Cl}^{-}$and standard internals, and the data from each internal were pooled.

Fluorescence imaging. The dendritic tree was visualized using either whole-field or two-photon fluorescence imaging. Whole-field fluorescence images were obtained using an Olympus BX50 microscope equipped with a $40 \times$ water-immersion objective (numerical aperture 0.8 ; Olympus), a monochromator-based imaging system (Polychrome V; T.I.L.L. Photonics), and a cooled CCD camera [either Imago QE (PCO Imaging) or Photon Max (Princeton Instruments)]. For calciumimaging experiments, the green fluorescent calcium indicator Oregon Green BAPTA-1 (50 $\mu \mathrm{M}$; Invitrogen) was added to the internal solution. Oregon Green BAPTA-1 was excited at $488 \mathrm{~nm}$. Calcium signals were calculated as change in fluorescence normalized to the baseline fluorescence $[\Delta F(t) / F 0]$.

Two-photon fluorescence images were obtained using a Carl Zeiss Axioskop 2FS with a 510 laser scanning head equipped with a Chameleon laser (Coherent) for two-photon excitation. For two-photon calciumimaging experiments, the green fluorescent calcium indicator Fluo 5F (300 $\mu \mathrm{M}$; Invitrogen) was added to the internal solution together with the red fluorescent calcium-insensitive Alexa Fluor 594 (30 $\mu \mathrm{M}$; Invitrogen). Fluo 5F and Alexa Fluor 594 were excited at $810 \mathrm{~nm}$. The emitted light was split with a dichroic (DT560), bandpass filtered (green channel, 500-560 nm; red channel, 575-640 nm), and detected with separate non-descanned detectors. Fluorescence images were acquired in linescan mode $(260 \mathrm{~Hz})$ at a resolution of $10-20$ pixels/ $\mu \mathrm{m}$. Small segments were selected over each subcellular region, and the fluorescence over this area was averaged. For two-photon sequences, calcium signals were calculated as the green fluorescence (Fluo $5 \mathrm{~F} ; K_{\mathrm{D}}$ of $\sim 2 \mu \mathrm{M}$ ) normalized to the red fluorescence (Alexa Fluor 594), $G / R(t)$. We estimated the calcium concentration using the following formula (Yasuda et al., 2004): $\left[\mathrm{Ca}^{2+}\right]=K_{\mathrm{D}}\left(G / R-(G / R)_{\min )} /\left((G / R)_{\max }-(G /\right.\right.$ $R)$ ). Calcium signals were analyzed offline with custom software written using LabVIEW (National Instruments).

Focal calcium release. Calcium-release experiments were performed with a UV spot positioning device (Prairie Technologies) that delivered light from a continuous-wave argon ion UV laser (Innova 300C; Coherent) via a single-mode fiber optic cable to the BX50 microscope at precise positions. The UV light was gated by an acousto-optical tunable filter and a Uniblitz VCM-D1 shutter (Vincent Associates). Neurons were loaded with the caged calcium reagent 1-(4,5-dimethoxy-2-nitrophenyl)-EDTA (DM-Nitrophen, $2 \mathrm{~mm}$ ) and $\mathrm{CaCl}_{2}(1.5 \mathrm{~mm}$ ) via the patch-clamp pipette together with the calcium indicator Oregon Green BAPTA-1 (50 $\mu \mathrm{M})$. In the internal solution, $\mathrm{Mg}_{2}$-ATP was replaced with equimolar $\mathrm{Na}-\mathrm{ATP}$. Apamin (100 nM) was added to the perfusate to block the SK channelmediated $I_{\mathrm{AHP}}$.

AHP shunt of EPSPs. EPSPs were evoked using either a monopolar stimulating electrode fabricated out of a patch pipette filled with ACSF or a bipolar stimulating electrode fabricated out of a double-barreled borosilicate pipette glass (TGC150-7.5; Harvard Apparatus) pulled to a $\sim 1$ $\mu \mathrm{m}$ tip. Stimulating electrodes were positioned 10-30 $\mu \mathrm{m}$ from a dendritic segment $\sim 100 \mu \mathrm{m}$ from the soma. Picrotoxin $(100 \mu \mathrm{M})$ and CGP $55845(10 \mu \mathrm{M})$ were added to the perfusate to antagonize $\mathrm{GABA}_{\mathrm{A}}$ and $\mathrm{GABA}_{\mathrm{B}}$ receptors, respectively. The sAHP was evoked using a $100 \mathrm{~ms}$ current injection adjusted to elicit four to six APs. The intensity of the isolated stimulator was adjusted to evoke an EPSP of $\sim 5 \mathrm{mV}$. Sequential presentations of the AHP + EPSP, EPSP alone, AHP alone, and a hyperpolarizing current step + EPSP were given at 20 s intervals. This sequence was repeated 7-15 times, and the data were averaged.

AHP shunt of APs. A $100 \mathrm{~ms}$ somatic current injection sufficient to elicit four to six APs was used to evoke a robust AHP. Calcium signals were imaged using two-photon fluorescence microscopy. Single APs were evoked alone (AP alone) or $500 \mathrm{~ms}$ after the AP train (AHP + AP) using a $5 \mathrm{~ms}, 1.2-2 \mathrm{nA}$ somatic current injection sufficient to elicit an AP under all conditions. The calcium response evoked by unpaired AP trains (AHP alone) was subtracted from the paired response to remove any residual calcium response of AP train from AP-evoked signal. In some trials, a $2 \mathrm{~s}$ somatic current injection was given to mimic the hyperpolarization during the AHP. Sequential presentations of the AHP + AP, AP alone, AHP alone, and a hyperpolarizing current step + AP were given at $20 \mathrm{~s}$ intervals. This sequence was repeated $5-10$ times, and the data were averaged.

Drugs. Drugs were bath applied unless specified otherwise. 1,2,3,4Tetrahydro-6-nitro-2,3-dioxo-benzo[f] quinoxaline-7-sulfonamide (NBQX) and 6-cyano-7-nitroquinoxaline-2,3-dione were prepared as stock solutions in DMSO and diluted in ACSF when required. NBQX and 2-amino-5phosphonovaleric acid were purchased from Tocris Bioscience. All other drugs were obtained from Sigma-Aldrich. Drugs were prepared as $1000 \times$ stock solutions and stored frozen $\left(-20^{\circ} \mathrm{C}\right)$ until required.

Statistics. Statistical analyses were performed with Statview (SAS Institute). Unless otherwise indicated, correlations were made using Fisher's $r$ to $z$, paired comparisons were made using paired Student's $t$ tests, and unpaired comparisons were performed using ANOVA or Student's $t$ tests as appropriate. All data are presented as mean \pm SEM unless otherwise indicated.

Computational modeling. Simulations were performed with the NEURON simulation program (version 7.0) (Hines and Carnevale, 1997). A realistic model of a BLA projection neuron was constructed based on morphological measurements from fluorescent $Z$-stacks of BLA projection neurons recorded in this study. This stylized neuron had an axon, soma, single apical dendrite, and five basal dendrites (supplemental Fig. $1 \mathrm{~A}$, available at www.jneurosci.org as supplemental material). The apical tree had 21 branches, 12 terminals, and 9 branch points. The 
primary apical dendrite was $50 \mu \mathrm{m}$ in length and $2.5 \mu \mathrm{m}$ in diameter. Secondary and higher-order branches were thinner, ranging from 1.3 to $0.6 \mu \mathrm{m}$ in diameter. Additionally, two oblique dendrites, $120 \mu \mathrm{m}$ in length and $0.8 \mu \mathrm{m}$ in diameter, arose from the primary apical dendrite. The total dendritic length of the apical tree was $1.95 \mathrm{~mm}$. Each basal dendrite had nine branches, five terminals, and four branch points. The primary basal dendrite was $15 \mu \mathrm{m}$ in length and $1.5 \mu \mathrm{m}$ in diameter. Secondary and higher branches ranged from 1.25 to $0.6 \mu \mathrm{m}$ in diameter. The total length of each basal dendrite was $810 \mu \mathrm{m}$. The soma had a 20 $\mu \mathrm{m}$ diameter. This morphology is consistent with previous descriptions of projection neurons in the BLA (McDonald, 1992; Faber et al., 2001). The model also used an axon that arose from the soma. It was modeled as an initial segment $75 \mu \mathrm{m}$ in length and $1.25 \mu \mathrm{m}$ in diameter and a main axon of $250 \mu \mathrm{m}$ in length and $0.5 \mu \mathrm{m}$ in diameter.

Despite differences in morphology, the active and passive membrane properties of projection neurons in the BLA are strikingly similar to those observed in hippocampal pyramidal neurons (Sah et al., 2003). Given that little is known about channel distribution and densities in BLA projection neurons, we applied channel densities and distributions from models of hippocampal pyramidal neurons (Gasparini et al., 2004) onto our BLA projection neuron morphology, making only minor adjustments to the channel density to better match our electrophysiological recordings. The model included a sodium current $\left(I_{\mathrm{Na}}\right)$, a calcium current $\left(I_{\mathrm{Ca}}\right)$, delayed rectifier and A-type potassium currents $\left(I_{\mathrm{KDR}}\right.$ and $\left.I_{\mathrm{A}}\right)$, and a hyperpolarization-activated nonspecific cation current $\left(I_{\mathrm{h}}\right)$. Although additional conductances are present in BLA neurons (Sah et al., 2003), this simplified model allowed us to replicate the basic biophysical properties of a BLA neuron while minimizing the assumptions necessary to incorporate these additional channel mechanisms and distributions. Briefly, $I_{\mathrm{KDR}}$ was uniformly distributed with a peak conductance of $30 \mathrm{pS}$ $\mu \mathrm{m}^{-2}$. The peak conductance of $I_{\mathrm{Na}}$ was $180 \mathrm{pS} \mu \mathrm{m}^{-2}$ in the soma and dendrite and was $360 \mathrm{pS} \mu \mathrm{m}^{-2}$ in the axon. As with hippocampal pyramidal neurons (Magee et al., 1998), BLA projection neurons contain L-, N-, P/Q-, and R-type voltage-dependent calcium channels (Foehring and Scroggs, 1994; Sah et al., 2003). Although the density of the individual channel subtypes varies with distance in hippocampal neurons, the total calcium channel density is relatively uniform (Magee et al., 1998). A composite calcium current $\left(I_{\mathrm{Ca}}\right)$ was used to represent the various types of voltage-dependent calcium channels. The peak conductance of $I_{\mathrm{Ca}}$ was set at $20 \mathrm{pS} \mu \mathrm{m}^{-2}$. The peak conductances for $I_{\mathrm{A}}$ and $I_{\mathrm{h}}$ were linearly increased with distance from the soma (Hoffman et al., 1997; Magee, 1999) up to $500 \mu \mathrm{m}$. The peak conductance for $I_{\mathrm{A}}$ was $132 \mathrm{pS} \mu \mathrm{m}^{-2}$ in the soma increasing with distance at $13.2 \mathrm{pS} \mu \mathrm{m}^{-2}$ every $10 \mu \mathrm{m}$. The peak conductance density for $I_{\mathrm{h}}$ was $0.3 \mathrm{pS} \mu \mathrm{m}^{-2}$ in the soma, increasing by $0.9 \mathrm{pS} \mu \mathrm{m}^{-2}$ every $10 \mu \mathrm{m}$. Gating mechanisms used for $I_{\mathrm{Na}}, I_{\mathrm{KDR}}, I_{\mathrm{A}}$, and $I_{\mathrm{h}}$ were identical to those described by Gasparini et al. (2004). The gating mechanisms for L-type voltage-dependent calcium channels modeled in hippocampal pyramidal neurons (Migliore et al., 1995) were used for $I_{\mathrm{Ca}}$.

A passive conductance ( $g_{\text {pas }}$ ) was set to $28.6 \mu \mathrm{S} \mathrm{cm}^{-2}$ with a reversal potential $\left(e_{\text {pas }}\right)$ of $-75 \mathrm{mV}$, yielding a somatic membrane potential of $-75.5 \mathrm{mV}$. The axial resistivity $\left(R_{\mathrm{a}}\right)$ was $150 \Omega \mathrm{cm}$, except in the axon in which it was $50 \Omega / \mathrm{cm}$. Membrane capacitance $\left(C_{\mathrm{m}}\right)$ was $1 \mu \mathrm{F} \mathrm{cm}{ }^{-2}$ in the axonal and somatic compartments. Despite their small volume, serial reconstructions indicate that the surface area of a spine is $\sim 0.83 \mu \mathrm{m}^{2}$ (Harris and Stevens, 1989), effectively doubling the surface area of thin dendrites. In accordance with hippocampal pyramidal neuron models (Migliore et al., 1995; Gasparini et al., 2004), the capacitance and passive conductance of dendritic compartments was doubled to account for spines. Because the primary dendrites have a larger diameter, the capacitance and passive conductance of the primary apical dendrite and primary basal dendrites were increased by only 30 and 50\%, respectively. Using these parameters, the model neuron closely matched our wholecell patch-clamp recordings (supplemental Fig. 1, available at www. jneurosci.org as supplemental material).

The $\mathrm{sI}_{\mathrm{AHP}}$ has slow kinetics (decay time constant $>1 \mathrm{~s}$ ) and is therefore essentially constant over the short time course of an AP, an EPSP, or a brief voltage step. Because the $s I_{\mathrm{AHP}}$ is voltage insensitive, the $s I_{\mathrm{AHP}}$ was implemented as an ohmic potassium conductance. Voltage-clamp re- cordings were modeled using the single-electrode voltage-clamp point process (SEClamp; $R_{\mathrm{s}}$ of $5 \mathrm{M} \Omega$ ) built into neuron. Somatic current injections were implemented using the IClamp point process.

Synaptic inputs were given both AMPA and NMDA conductances and placed on the apical dendrite ( $150 \mu \mathrm{m}$ from the soma). Both conductances were given a reversal potential of $0 \mathrm{mV}$. The AMPA conductance decayed exponentially with a time constant of $3 \mathrm{~ms}$. The NMDA conductance had a dual-exponential decay, implemented using the following formula: $g_{\max } *\left(1-\left(\right.\right.$ frac ${ }^{*} e^{-t / \tau 1}+(1-$ frac $\left.) * e^{-t / \tau 2}\right)$, where $g_{\max }$ is the maximum conductance, $\tau 1$ is the fast decay time constant, $\tau 2$ is the slow decay time constant, and frac is the relative contribution of the $\tau 1$ to the peak current amplitude. Because kinetics and pharmacology of synaptically evoked NMDA currents suggest that they are mediated by NR2A subunit-containing NMDA receptors (Lopez de Armentia et al., 2003), $\tau 1, \tau 2$, and frac were assigned $16.5 \mathrm{~ms}, 123.5 \mathrm{~ms}$, and 0.90 , respectively. These deactivation time constants correspond to values from recombinant expression systems (Vicini et al., 1998), which have been adjusted to approximate $31^{\circ} \mathrm{C}$ recording conditions in the present study. The voltage-dependent $\mathrm{Mg}^{2+}$ block was incorporated using the following formula: Mgblock $=1 /\left(1+e^{-0.062 * V \mathrm{~m}}\right) *\left(\left[\mathrm{Mg}^{2+}\right]_{\mathrm{o}} / 3.57\right)(\mathrm{Jahr}$ and Stevens, 1990). The extracellular $\mathrm{Mg}^{2+}$ concentration, $\left[\mathrm{Mg}^{2+}\right]_{\mathrm{o}}$, was set to $1.3 \mathrm{~mm}$, the concentration present in the ACSF.

\section{Results}

Whole-cell patch-clamp recordings were made from projection neurons within the basal nucleus of the BLA. In response to a depolarizing current injection, these neurons fired a train of APs that evoked a rapid rise in calcium in the soma and dendrites and was followed by a prolonged AHP (Fig. $1 A$ ). In these neurons, the AHP is primarily attributable to the activation of two calciumactivated potassium currents, the apamin-sensitive $I_{\mathrm{AHP}}$ and the apamin-insensitive $s I_{\mathrm{AHP}}$, that mediate the medium AHP and sAHP, respectively (Power and Sah, 2008). When the currents are evoked under voltage-clamp conditions (100 ms voltage step from -50 to $0 \mathrm{mV}$ ), the difference in the time course of these currents is clear (Fig. $1 B$ ). The $I_{\mathrm{AHP}}$ is mediated by SK-type calcium-activated potassium channels, and its time course primarily follows cytosolic calcium, rising rapidly after APs and decaying with a time constant of 50 to several hundred milliseconds (Sah and Faber, 2002). In contrast, the kinetics of the $s I_{\mathrm{AHP}}$ do not track the calcium rise (Jahromi et al., 1999; Sah and Clements, 1999) but rather has a much slower time course, rising to a peak after the calcium response and lasting several seconds (Fig. $1 A, B)$. Consistent with previously published results from hippocampus (Knöpfel et al., 1990; Müller and Connor, 1991) and the BLA (Sah and Faber, 2002; Power and Sah, 2008), application of NA suppressed the sAHP (Fig. $1 A$ ) and the corresponding $s I_{\mathrm{AHP}}$ with no effect on the calcium rise (Fig. 1A,B). The integrated area of the sAHP evoked by an AP train (four APs, $100 \mathrm{~ms}$ ) was reduced by $99 \pm 1 \%$, whereas the integrated area of the calcium rise in the dendrite and soma was unaffected $(81 \pm 17$ and $119 \pm 30 \%$ of control in the soma and proximal dendrite, respectively; $n=3$ ). The outward tail current remaining in the presence of NA was blocked by apamin (100 nM), confirming it as $I_{\mathrm{AHP}}($ Fig. $1 B)$.

\section{Localization of the $s I_{\mathrm{AHP}}$}

To estimate the location of the channels that underlie the $s I_{\mathrm{AHP}}$, we took advantage of space-clamp problems associated with voltage clamping neurons with extended dendritic trees, such as projection neurons in the BLA, by measuring the time required for the current to fully adapt to a shift in the command potential at the soma (Isaacson and Walmsley, 1995; Sah and Bekkers, 1996). The time course of this adaptation reflects the time required for the voltage-clamp command to spread from the soma 
A

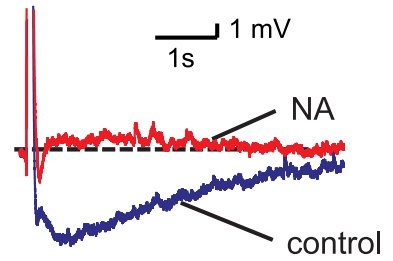

I $10 \mathrm{mV}$

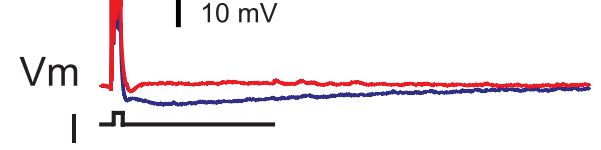

soma
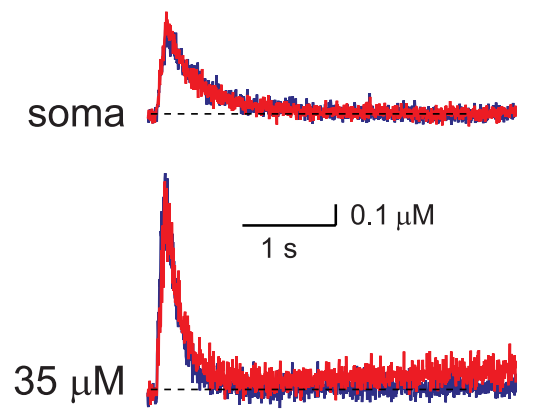

B

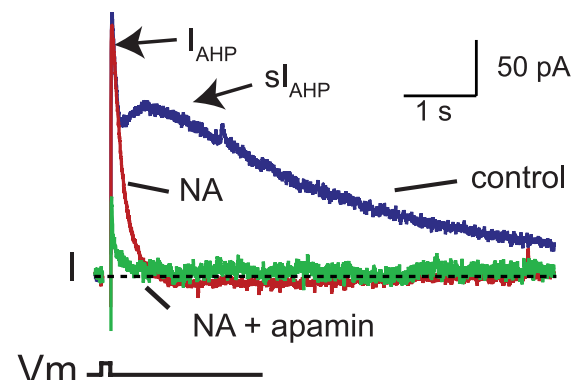

$\mathrm{Vm} \Omega$

Figure 1. Noradrenaline suppresses the SAHP without an effect on calcium influx. A, A $100 \mathrm{~ms}$ somatic current injection evokes a train of four APs that is followed by a slow AHP. The AHP is shown on an expanded scale in the inset. The neuron was loaded with the calcium indicator Fluo $5 \mathrm{~F}(50 \mu \mathrm{m})$ and the calcium-insensitive Alexa Fluor 594. The calcium response measured in the soma and proximal dendrite $35 \mu \mathrm{m}$ from the soma are shown in the traces below. Application of $10 \mu \mathrm{MNA}$ (red traces) suppresses the sAHP with no effect on calcium transients. $\boldsymbol{B}$, The current underlying the slow AHP is shown recorded in voltage clamp. Neurons were clamped to $-50 \mathrm{mV}$ and that AHP was evoked using a 100 $\mathrm{ms}$ step to $0 \mathrm{mV}$. Arrows point to the $I_{\text {AHP }}$ and $I_{\text {AHP. }}$. Application of $10 \mu \mathrm{M} N$ N (red trace) suppresses the $s I_{A H P}$ but not the $I_{\text {AHP. }}$. Subsequent application of the $S K$ channel blocker apamin (100 nM; green trace) blocks the $I_{\text {AHP. }}$.

to the current source, as well as the filtering of the resulting change in the current as it spreads from its origin to the somatic voltage-clamp electrode (Jack et al., 1983; Spruston et al., 1994; Häusser and Roth, 1997). We evoked the $s I_{\mathrm{AHP}}$ by applying a $100-200 \mathrm{~ms}$ voltage step to $0 \mathrm{mV}$ from a holding potential of -50 $\mathrm{mV}$, after which a $20 \mathrm{mV}$ hyperpolarizing voltage step was applied during the $\mathrm{sI}_{\mathrm{AHP}}$ (Fig. $2 \mathrm{~A}$ ). The hyperpolarizing voltage step was applied $700 \mathrm{~ms}$ after the onset of the depolarizing voltage step to avoid contamination by the faster decaying apamin-sensitive $I_{\mathrm{AHP}}$. Digital subtraction of the voltage step delivered with or without evoking the $s I_{\mathrm{AHP}}$ allowed us to assess the time course of relaxation of the $s I_{\mathrm{AHP}}$ (Fig. $2 \mathrm{~A}$ ). This current "switch-off" was not instantaneous, and its time course was well fit by a single exponential with a mean time constant of $4.7 \pm 0.4 \mathrm{~ms}(n=33)$.

To estimate the electrotonic location of the $s I_{\mathrm{AHP}}$, we compared the time constant of the $s I_{\mathrm{AHP}}$ relaxation to the relaxation time constant obtained for $\mathrm{GABA}_{\mathrm{A}}$ currents activated at known dendritic locations. To enable this comparison, we increased the chloride concentration of the internal solution (to $76 \mathrm{~mm}$ ) and voltage clamped the neuron to $-80 \mathrm{mV}$. This configuration yielded a chloride reversal potential of $-14 \mathrm{mV}$ and a driving force of $76 \mathrm{mV}$, similar to the $57 \mathrm{mV}$ driving force for the $s I_{\mathrm{AHP}}$. GABA was focally applied in the presence of $\mathrm{GABA}_{\mathrm{B}}$ receptor antagonists to evoke a small inward current $(134 \pm 17 \mathrm{pA} ; n=$ 14) that was blocked by picrotoxin (data not shown), confirming that it is attributable to activation of $\mathrm{GABA}_{\mathrm{A}}$ receptors. During the GABAergic current, the command potential was depolarized by $20 \mathrm{mV}$, reducing the driving force of the current. The relaxation of the GABA current was well fit with a single exponential with a time constant that was correlated with its distance from the soma $(r=0.843 ; p<0.0001)$ (Fig. $2 C, D)$, with currents evoked farther from the soma being slower to adapt to the new command potential. When applied within $50 \mu \mathrm{m}$ from the soma, the mean time course of GABA current adaptation was $1.4 \pm 0.3 \mathrm{~ms}(n=3)$ compared with $6.5 \mathrm{~ms}(n=2)$ when GABA was applied 195-205 $\mu \mathrm{m}$ from the soma. The relaxation time constant of the $I_{\mathrm{AHP}}$ was similar to the response time observed when GABA was applied $100 \mu \mathrm{m}$ from the soma, suggesting that channels that underlie the $s I_{\mathrm{AHP}}$ are likely located at some distance from the soma.

To confirm our experimental prediction for the location of the $s I_{\mathrm{AHP}}$, we constructed a computational model of a BLA projection neuron. The model neuron had a realistic morphology based on morphological measurements from neurons recorded in this study (supplemental Fig. 1, available at www.jneurosci.org as supplemental material) and was voltage clamped at the soma. An $s I_{\mathrm{AHP}}$ conductance added on either the soma or the dendrites at various distances from the soma and its amplitude adjusted to generate a somatic current of $100 \mathrm{pA}$. As done experimentally (Fig. 2A), subtraction of the current response to a $100 \mathrm{~ms},-20$ $\mathrm{mV}$ voltage shift in the absence of the $s I_{\mathrm{AHP}}$ conductance from the response to a voltage shift with an active $s I_{\mathrm{AHP}}$ conductance revealed the predicted $s I_{\mathrm{AHP}}$ relaxation time course in response to the voltage step (Fig. $2 E$ ). As expected, the model predicts that the relaxation time constant will increase with distance from the somatic patch-clamp electrode. Importantly, the relaxation time constants generated by our model are strikingly similar to those obtained experimentally (Fig. $2 E)$. Moreover, the model shows that, over the range of $50-$ $200 \mathrm{pA}$, similar to peak $s I_{\mathrm{AHP}}$ currents in this study, current amplitude has little impact on the relaxation time course (supplemental Fig. 2, available at www.jneurosci.org as supplemental material). Together, these results are consistent with our proposal that the $s I_{\mathrm{AHP}}$ may be largely extrasomatic.

\section{Focal uncaging of calcium}

The $s I_{\mathrm{AHP}}$ is a calcium-dependent potassium current that can also be evoked by uncaging cytosolic calcium (Lancaster and Zucker, 1994; Sah and Clements, 1999). We next examined the location of the $s I_{\mathrm{AHP}}$ by examining currents evoked in response to spatially restricted calcium rises. Neurons were loaded with a caged calcium reagent, 1-(4,5-dimethoxy-2-nitrophenyl)-EDTA (2 mM). Apamin was added to the perfusate to eliminate the SK channelmediated $I_{\mathrm{AHP}}$. Using a focused UV laser, we were able to photorelease calcium in a spatially restricted manner. When the laser was focused on the soma, brief pulses of UV excitation ( $10 \mathrm{~ms}, 20$ $\mathrm{mW}$ ) evoked a calcium rise that was primarily restricted to the soma (Fig. $3 A, B$ ). In contrast, depolarizing voltage steps ( $200 \mathrm{~ms}$, $65 \mathrm{mV}$ ) raised intracellular calcium both in the soma and throughout the dendritic tree. Although our UV pulse and volt- 
age steps produced comparable rises in somatic calcium, the outward current evoked by the UV pulse was a fraction of that evoked by the voltage step $(n=11)$ (Fig. 3C). The peak amplitude and integrated area of the somatic calcium rise evoked by the UV pulse were $108 \pm 12 \%$ $(p=0.62)$ and $110 \pm 18 \%(p=0.53)$, respectively, of the calcium rise evoked by the voltage step. The peak amplitude and integrated area of the $s I_{\mathrm{AHP}}$ evoked by the UV pulse were $15 \pm 3 \%(p=0.0002)$ and $16 \pm 4 \%(p=0.0001)$, respectively, of that evoked by the voltage step. The BLA is not a laminar structure, and dendrites radiate from the soma in three dimensions. Because the dendritic arbors are also erratically distributed, rarely maintaining a consistent orientation (McDonald, 1992; Rainnie and Shinnick-Gallagher, 1992; Washburn and Moises, 1992a; Power and Sah, 2007), systematic mapping of the dendrites was not possible. However, we have tested uncaging calcium over small segments of dendrite, $70-100 \mu \mathrm{m}$ from the soma, within the same focal plane as the soma, where we predict $s I_{\mathrm{AHP}}$ channels are located (Fig. 3D--F). Such focal uncaging evoked a detectable current in four of five neurons. The amplitude and integrated area of the UV evoked current were $18 \pm 10 \%$ and $23 \pm 14 \%$ of the voltage step response respectively, smaller than the current evoked by the voltage step (peak, $p=0.002$; area, $p=0.01 ; n=$ 5 ) but not significantly different from the current evoked by somatic uncaging of calcium (peak, $p=0.43$; area, $p=0.57$ ). These data, and the failure of somatic calcium rises to reproduce the $s I_{\mathrm{AHP}}$, are consistent with our proposal that this current is primarily extrasomatic.

\section{The AHP shunts EPSPs}

Because the sAHP appears to have a dendritic location, we next tested whether its activity may have a role in controlling the propagation of synaptic responses from the dendrite to the soma, via either their hyperpolarizing or shunting actions (Sah and Bekkers, 1996). Stimulating electrodes were placed near a dendrite of interest 100-200 $\mu \mathrm{m}$ from the soma, and EPSPs evoked during the SAHP were compared with those evoked at rest (Fig. $4 A$ ). EPSPs evoked during the sAHP were smaller in amplitude and decayed faster than control EPSPs (Fig. $4 B--E)$. When the $s A H P$ was $>2 \mathrm{mV}$, the amplitude of the EPSP was reduced by $7 \pm 3 \%(p=0.049)$, whereas the rise time and decay time constant were reduced by $11 \pm 3 \%(p=0.008)$ and $32 \pm 4 \%(p<0.0001)$, respectively $(n=12)$, and were correlated with the amplitude of the SAHP $(r=0.610 ; p=0.008)$ (Fig. $4 F)$. In contrast, hyperpolarizing the neuron via somatic current in-
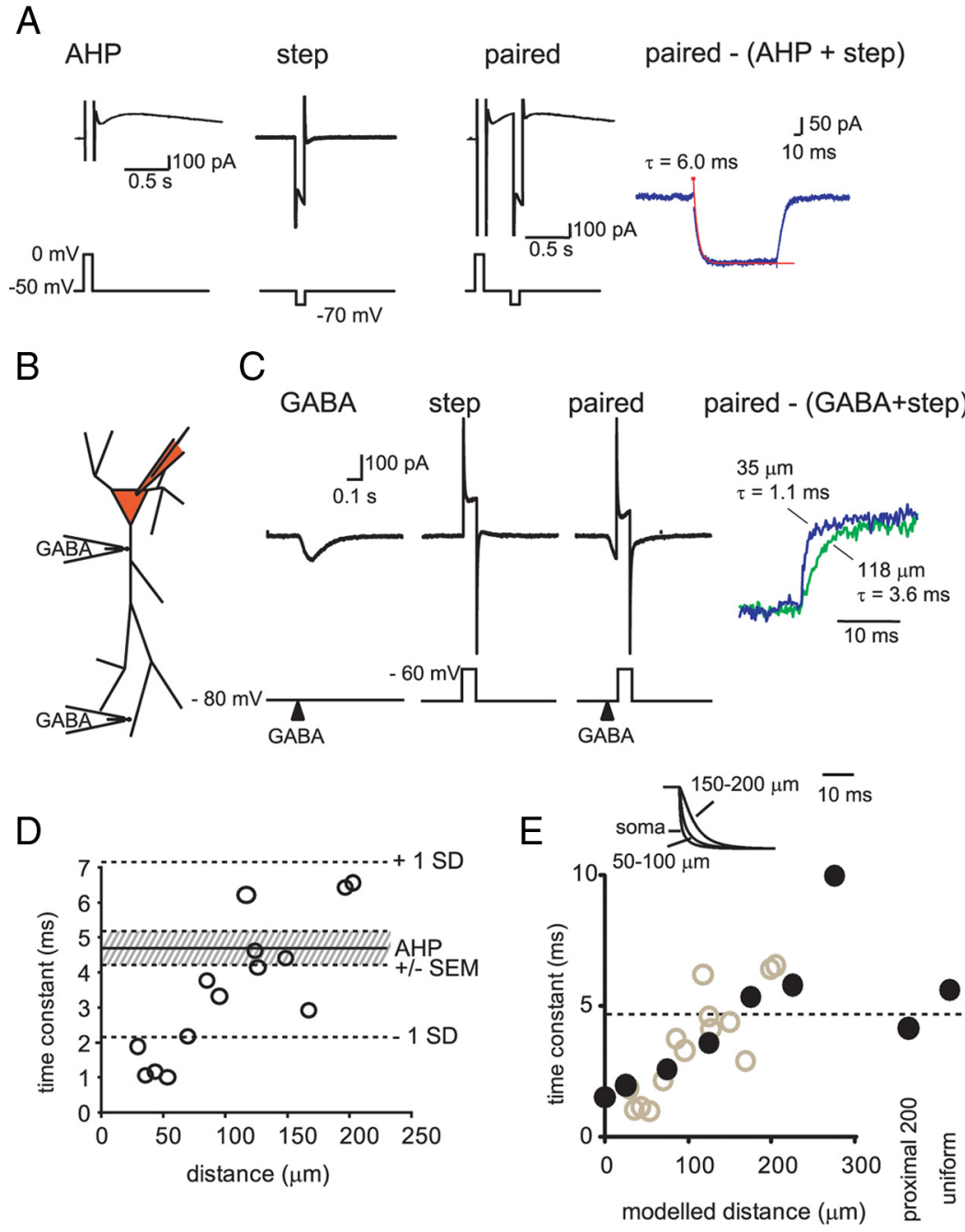

Figure 2. Channels underlying the $S A H P$ are primarily located on the dendritic tree. $\boldsymbol{A}$, The $\mathrm{S}_{\mathrm{AHP}}$ evoked by a voltage $\mathrm{step}$ to $0 \mathrm{mV}$ from a holding potential of $-50 \mathrm{mV}$ (traces on left); the response to a $20 \mathrm{mV}$ hyperpolarizing step is shown in the middle traces, and the response to a hyperpolarizing step during the $s I_{A H P}$ is shown on the right (paired). The relaxation of the $s I_{A H P}$ during the voltage step is plotted together with its exponential fit in the inset. The initial points from the peak capacitive transient were clipped in the digitization process, and the resulting subtraction artifact was blanked. $\boldsymbol{B}$, Diagram depicting the experimental design is shown. Neurons were filled with either Alexa Fluor 488 or Alexa Fluor 594 to visualize the dendritic tree, and GABA (50 $\mu \mathrm{m})$ was focally applied to the dendrite at various distances from the soma. C, Whole-cell current evoked by focal application of GABA to the proximal dendrite (GABA), a $20 \mathrm{mV}$ depolarizing voltage step (step), and a $20 \mathrm{mV}$ voltage step during application of $G A B A$ (paired). Digital subtraction of the summated response of GABA application and the voltage step from the combined response revealed the GABA current as it adjusted to the $20 \mathrm{mV}$ voltage step. The inset shows the settling of normalized GABA current for focal application of GABA at two different locations onto the same neuron (35 and $118 \mu \mathrm{m}$ from the soma). $\boldsymbol{D}$, The time constant of the GABA current relaxation is plotted against the distance of the GABA-containing pipette from the soma. The horizontal lines

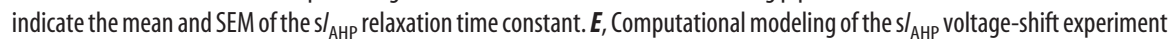
shows that the relaxation time course is dependent on the distance of the conductance from the somatic patch-clamp electrode. The predicted relaxation time constant (black circles) is plotted for $\mathrm{s}_{\text {AHP }}$ conductances placed on the soma and on the dendrite at various distances from the soma. Also plotted are the calculated results from distributing the $\mathrm{s}_{\text {AHP }}$ along the first $200 \mu \mathrm{m}$ of dendrite (proximal 200) and uniformly throughout the neuron. The amplitude of the conductance was adjusted so that each distribution generated a $100 \mathrm{pA}$ somatic current. The gray circles show the experimental data for focal GABA application from $\boldsymbol{D}$. Inset shows the predicted settling current in response to a $20 \mathrm{mV}$ voltage step for a somatic and dendritic (50-100 and 150-100 $\mu \mathrm{m})$ channel distributions. The dashed line indicates the $s /_{\text {AHP }}$ relaxation time constant.

jection tended to increase EPSP amplitude (104 $\pm 3 \%$ of control; $n=7$; hyperpolarization vs control, $p=0.20$; hyperpolarization vs AHP, $p<0.001$ ), presumably by enhancing the driving force of the synaptic current, with no change in EPSP kinetics (Fig. $4 C, E$ ). Thus, the effects of the sAHP on the EPSP most likely result from the shunting rather than the hyperpolarizing actions of the sAHP. 
A

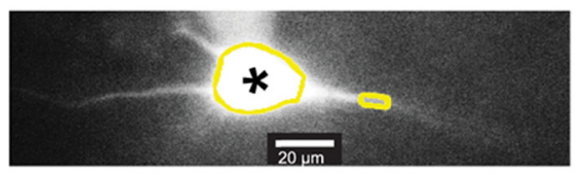

C

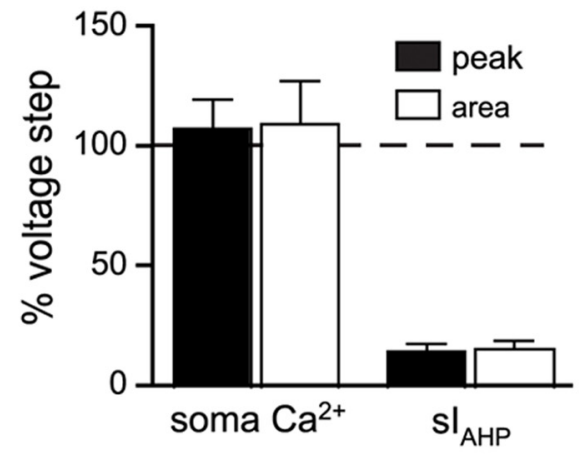

B

voltage step uncage $\mathrm{Ca}^{2+}$ voltage step

I
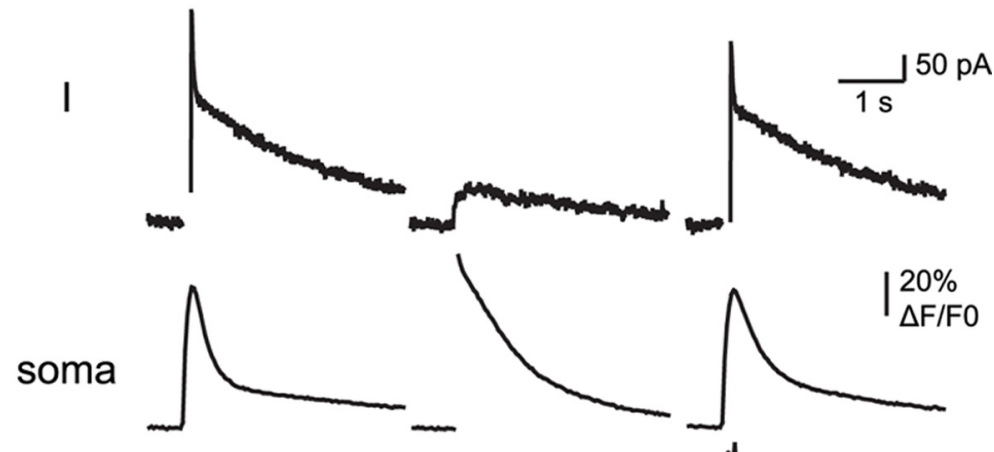

dend
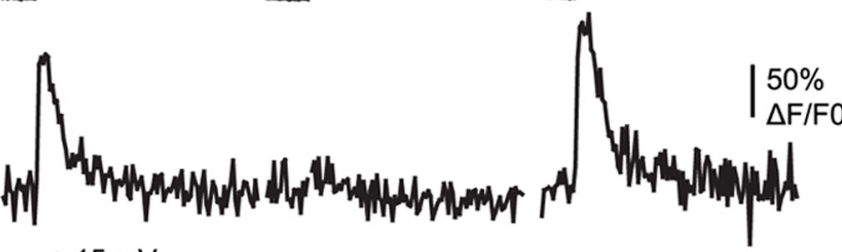

$\mathrm{Vm}_{-50 \mathrm{mV}} \mathrm{r}_{24 \mathrm{~s} \triangle \mathrm{UV}}$
D

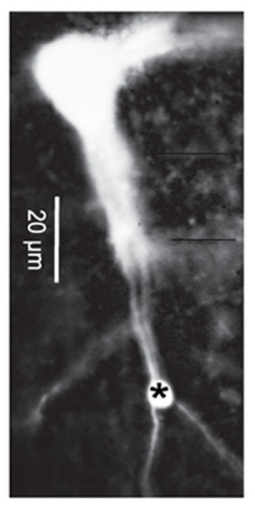

E

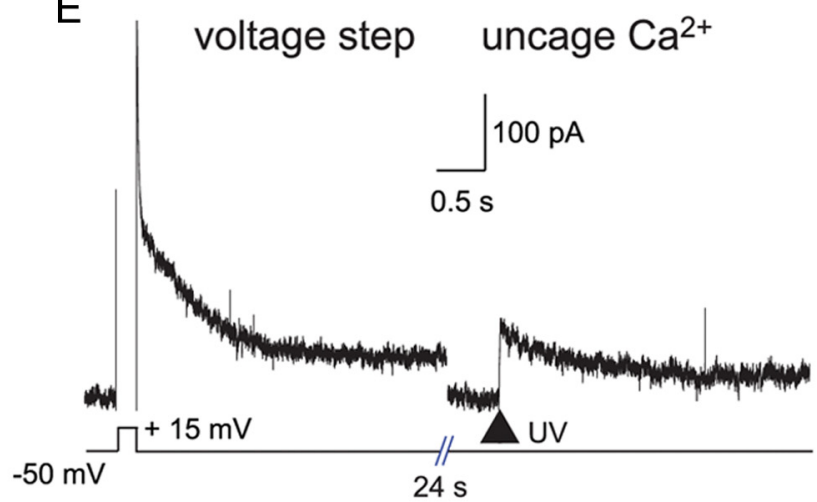

$\mathrm{F}$

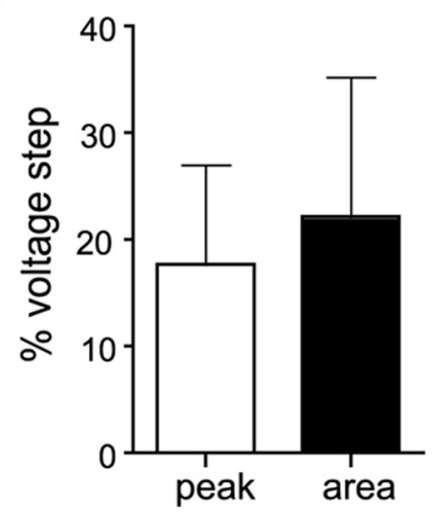

Figure 3. Somatically restricted calcium rises fail to reproduce the $\mathrm{S}_{\text {AHP }}$. $\boldsymbol{A}$, Green fluorescence image of a BLA neuron filled with the calcium indicator Oregon Green BAPTA-1, together with the photosensitive calcium buffer DM-Nitrophen $(2 \mathrm{~mm})$. Yellow boxes indicate the somatic and the dendritic regions of interest. * indicates the position of the UV uncaging spot. $\boldsymbol{B}$, The whole-cell current and calcium response to a $200 \mathrm{~ms}, 65 \mathrm{mV}$ voltage step from a holding potential of $-50 \mathrm{mV}$ bracketing (left and right traces) the response to a flash of UV laser light directed at the soma (middle traces). The arrowhead indicates the timing of the UV laser pulse $(10 \mathrm{~ms}, 20 \mathrm{~mW})$ used to uncage calcium in the soma. The artifact caused by the UV laser was removed from the calcium traces. $C$, Summary data showing the amplitude $\left(500 \mathrm{~ms}\right.$; white bars) and the integrated area $\left(0.5-3 \mathrm{~s}\right.$; black bars) of the $\mathrm{s}_{\mathrm{AHP}}$ current and calcium response evoked by photorelease of calcium in the soma, normalized to the response evoked by a voltage step $(n=11)$. $\boldsymbol{D}$, Fluorescence image of the BLA neuron in which the UV laser was directed at a segment of dendrite $90 \mu \mathrm{m}$ from the soma. ${ }^{*}$ indicates the position of the UV uncaging spot. $\boldsymbol{E}$, An example of the I $_{\text {APP }}$ Current evoked by photolytic uncaging of calcium (left traces) in the dendrite of the neuron shown in $\boldsymbol{D}$. The current trace is the average response evoked by six UV stimulations. The current evoked by a voltage step in this neuron is shown on the left. $\boldsymbol{F}$, Summary data showing the amplitude (500 $\mathrm{ms}$; white bars) and the integrated area $(0.5-3 \mathrm{~s})$ of the $s_{\text {AHP }}$ current evoked by photorelease of calcium in the dendrite $(70-100 \mu \mathrm{m}$ from the soma), normalized to the response evoked by a voltage step $(n=5)$.

\section{Pharmacology of sAHP-mediated EPSP modulation}

To confirm that hastening of the EPSP that followed the AP train resulted from activation of $s I_{\mathrm{AHP}}$, we suppressed the $\mathrm{sAHP}$ by the inclusion of the calcium chelator BAPTA in the intracellular solution. Neither the sAHP nor the hastening of the EPSP after the AP train was observed in the presence of BAPTA $(10 \mathrm{~mm})$ (Fig. $4 G, J, K)$. In BAPTA-loaded neurons, the sAHP after AP trains was $0.3 \pm 0.1 \mathrm{mV}(n=6)$, and the amplitude and decay of the EPSP during the sAHP were $110 \pm 5 \%(p=0.053)$ and $100 \pm 4 \%$ $(p=0.88)$ of control, respectively $(n=6$; BAPTA vs control; $p=$ 0.01 and $p=0.00017$ ), indicating that both the attenuation of the EPSP and the sAHP are similarly calcium dependent.

In addition to its calcium dependence, the $s I_{\mathrm{AHP}}$ is also sensitive to a variety of neuromodulatory transmitters, which uncouple the $s I_{\mathrm{AHP}}$ from the calcium rise (Fig. 1) (Müller and Connor, 1991; Sah and Clements, 1999). Bath application of noradrena- line reduced the sAHP by $87 \pm 5 \%(n=4 ; p=0.004)($ Fig. $4 H, J)$. Importantly, AP trains in the presence of noradrenaline had no effect on the decay of the EPSP (Fig. $4 H, K$ ). After the AP train, the EPSP decay was $66 \pm 10 \%$ of control before the application of noradrenaline and $101 \pm 4 \%$ of control in the presence of noradrenaline $(n=4 ; p=0.06)$. The EPSP amplitude after the AP train was $97 \pm 7 \%$ of control before the application of noradrenaline and $98 \pm 5 \%$ of control in the presence of noradrenaline. Notably, noradrenaline did reduce EPSP amplitude $(4.4 \pm 0.4$ to $2.6 \pm 0.2 \mathrm{mV} ; p=0.015)$ and decay time constant $(39.2 \pm 5.1$ to $23.8 \pm 5.0 \mathrm{~ms} ; p=0.01$ ) of the control EPSP, presumably because of activation of presynaptic $\alpha$-adrenergic receptors (Ferry et al., 1997; DeBock et al., 2003). Because the results with noradrenaline may have also been compromised by adrenergic modulation of EPSPs through its actions on SK calcium-activated potassium channels (Faber et al., 2008), the experiment was repeated using 
the $\beta$-adrenergic agonist isoprenaline in the presence of the apamin $(100 \mathrm{~nm})$ to eliminate any potential SK channelmediated effects. Similar to previous reports (Faber and Sah, 2002; Power and Sah, 2008), apamin had little effect on the sAHP (Fig. $4 I, J)$. In the presence of apamin, the sAHP after the AP train was $4.7 \pm 7 \mathrm{mV}(n=9)$. Apamin had no significant effect on the modulation of the EPSP during the SAHP (Fig. $4 J, K$ ), and, in its presence, the EPSP still decayed faster during the sAHP (65 \pm $4 \%$ of control; $p=0.0003$ ). Although we did not observe a reduction in the EPSP amplitude during the sAHP (101 $\pm 4 \%$ of control; $p=0.96)$, neither the change in EPSP amplitude $(p=0.13)$ nor the change in the EPSP decay time constant $(p=0.91)$ during the sAHP were significantly different from that in apamin-free controls. Subsequent application of isoprenaline $(10 \mu \mathrm{M})$ reduced the SAHP by $73 \pm 8 \%(n=4)$ and attenuated the reduction of the EPSP decay during the sAHP (Fig. 4I). During the sAHP, the EPSP decay time constant increased from $66 \pm 5 \%$ of control before application of isoprenaline to $88 \pm 8 \%$ of control in the presence of isoprenaline $(p=$ $0.018)$.

\section{AHP attenuates synaptic integration}

Our finding that EPSPs decay faster when evoked during the sAHP suggests that synaptic summation may also be altered during the sAHP. To test this possibility, a brief train of EPSPs $(250 \mathrm{~ms}, 20 \mathrm{~Hz})$ was evoked before and during the sAHP. Experiments were performed in the presence of picrotoxin and CGP 55845 to block GABAergic synaptic potentials and apamin to eliminate SK channel-mediated actions. We found that both temporal summation (Fig. 5A--C) and the integrated area of the EPSP train (Fig. 5D) were reduced during the SAHP $(n=9)$. The summated postsynaptic potential was reduced by $40 \pm 6 \%$ during the sAHP $(p=0.0013 ; n=9)$. Isoprenaline was subsequently applied to reduce the sAHP. Under these conditions, addition of isoprenaline frequently made neurons hyperexcitable to the synaptic trains. Recurrent activation and the potentiation of synaptic potentials were often observed, resulting in the generation of APs during the synaptic trains. In the few instances (three of nine) in which these effects were not observed, isoprenaline reduced the SAHP and restored the synaptic summation (Fig. $5 E$ ).

\section{AHP reduces the AP-evoked calcium rise}

The above results demonstrate that the sAHP shunts the EPSP and limits the in-
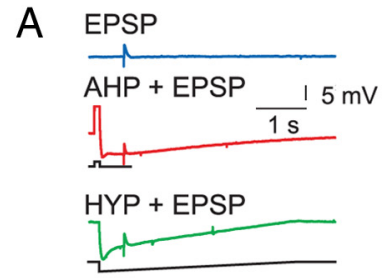

D
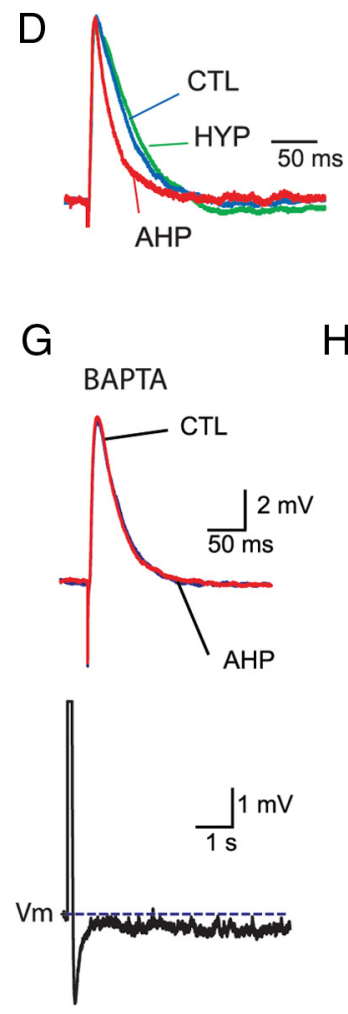

$\mathrm{H}$
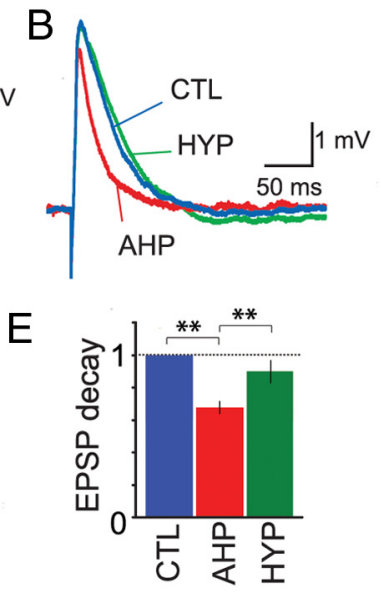

CTL

NA

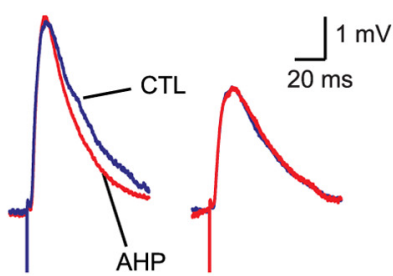

$\mathrm{F}$

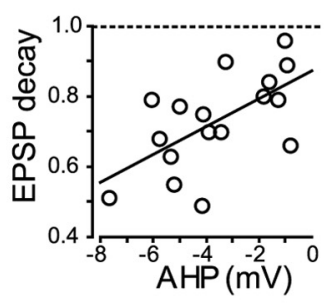

I
C

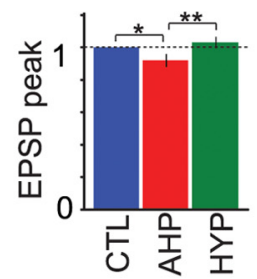


A

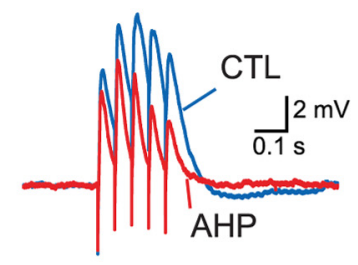

B
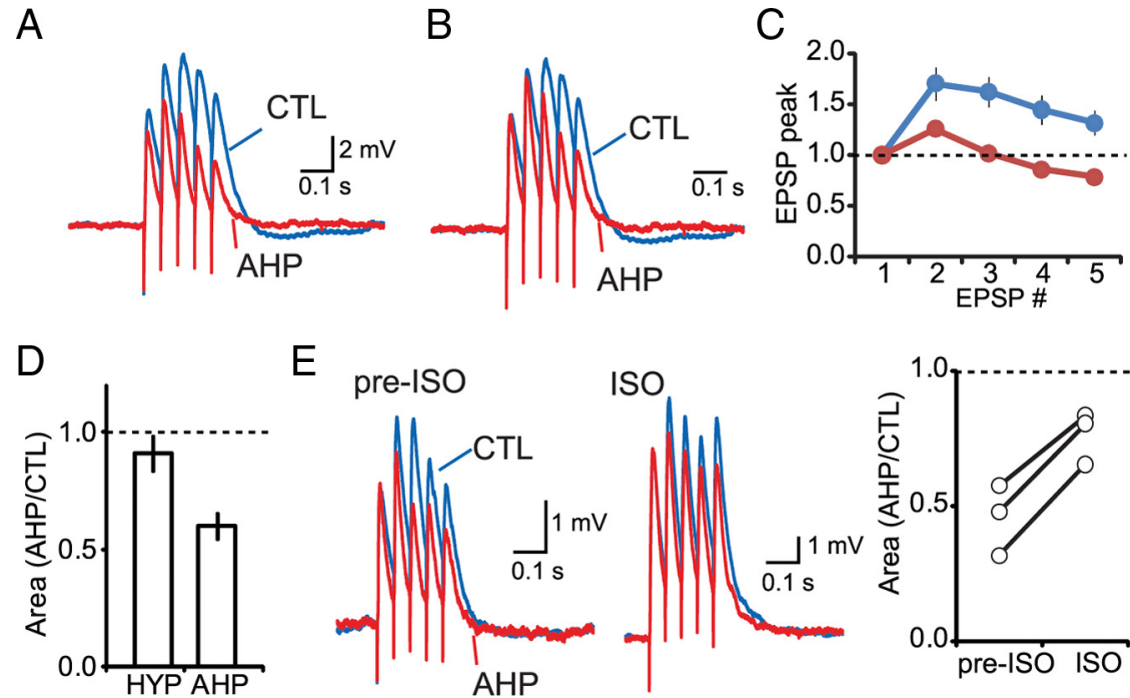

E
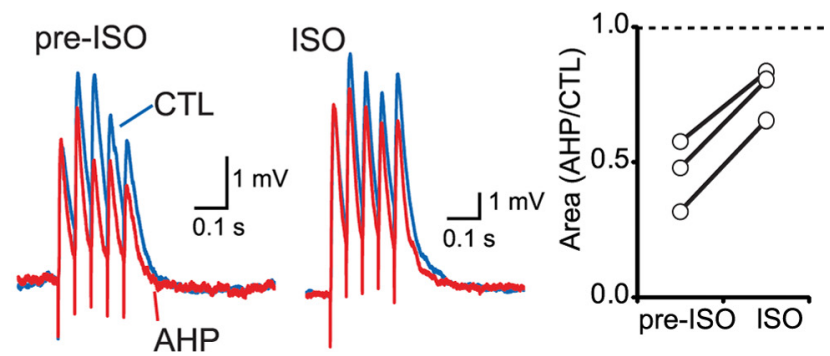

Figure 5. EPSP summation is reduced during the SAHP. A, Representative voltage responses to brief trains of synaptic stimulation (100 ms, $20 \mathrm{~Hz}$ ) under control conditions (CTL; blue) and during the SAHP (AHP; red). Trains were evoked in the presence of apamin, picrotoxin, and CGP 55845. $\boldsymbol{B}$, EPSP trains, shown in $\boldsymbol{A}$, plotted normalized to the amplitude of the first EPSP amplitude in the train. C, Summary data of the amplitude of each EPSP in the train normalized to the first EPSP $(n=9)$. Summary results showing the normalized integrated synaptic potential of the trains evoked during the SAHP (AHP) and during a hyperpolarizing current injection (HYP) are plotted in $\boldsymbol{D}$. $\boldsymbol{E}$, Summating synaptic potentials under control conditions and during the SAHP before (pre-ISO) and after application of isoprenaline (ISO). The integrated synaptic potential during the SAHP (normalized to control) plotted before and after application of isoprenaline is shown in the same panel for three individual neurons.

\section{Modeling the impact of the sAHP}

Our switch-off (Fig. 2) and focal uncaging data (Fig. 3) indicate that the majority of channels underlying the $\mathrm{SI}_{\mathrm{AHP}}$ are located on the dendritic tree, and activation of the slow AHP attenuates synaptic potentials (Fig. 4) and the AP-evoked dendritic calcium response (Fig. 6). A number of locations for the $s I_{\mathrm{AHP}}$ have been proposed, including the soma (Lima and Marrion, 2007), apical dendrites (Sah and Bekkers, 1996), or basal dendrites (Bekkers, 2000). To determine the possible distributions of the sAHP that may explain these data, we used simulated results using a computational model of a BLA projection neuron (see Materials and Methods). We compared model configurations that implemented the $s I_{\mathrm{AHP}}$ uniformly throughout the neuron, on the soma only, on the basal dendrites only, or uniformly throughout along the proximal $200 \mu \mathrm{m}$ of the dendritic tree. For each configuration, the $s I_{\mathrm{AHP}}$ conductance was adjusted to yield a $5 \mathrm{mV}$ hyperpolarization of the somatic membrane potential. The effect of these distributions on simulated EPSPs generated by synapses placed on the apical den-

tegration of synaptic potentials. We next examined whether the sAHP also modulates signals that propagate from the soma to the dendrite. Neurons were loaded with the calcium indicator Fluo $5 \mathrm{~F}(300 \mu \mathrm{M})$, and the fluorescence response was measured at various dendritic locations. Brief ( $5 \mathrm{~ms}$ ) somatic current injections were used to evoke APs that led to a rapid rise in calcium throughout the dendritic tree. Similar to studies in other brain regions (Callaway and Ross, 1995; Markram et al., 1995; Schiller et al., 1995; Waters et al., 2005), the AP-evoked calcium response was largest in the proximal dendrites and attenuated at more distal dendritic locations (Spearman's rank correlation; $r=$ $-0.604 ; n=23$; $p=0.004$ ) (Fig. 6C). To test whether the APevoked calcium response is altered during the sAHP, we compared the AP-evoked calcium response during the sAHP with the response under control conditions (Fig. 6A, $B$ ). To isolate the calcium rise evoked by the AP from any residual calcium from the previous AP train, the response evoked by unpaired AP trains (AHP only) was subtracted from the paired response (AHP + $\mathrm{AP})$. This revealed that the AP-evoked calcium response was attenuated during the sAHP (Fig. $6 A, B, D$ ). The reduction of the AP-evoked calcium response was not significantly correlated with distance from the soma $(r=-0.24 ; p=0.22)$ (Fig. $6 D)$. For dendritic segments $70-150 \mu \mathrm{m}$ from the soma, the integrated area of the AP-evoked calcium response was reduced by $40 \pm 5 \%$ during the AHP ( $p=0.0004 ; n=18)$. Hyperpolarizing current injections mimicking the sAHP had a significantly smaller effect on the AP-evoked calcium rise (Fig. $6 D$ ), reducing the APevoked calcium rise by $14 \pm 6 \%$ ( $p=0.02$ vs control; $p=0.008$ vs AHP; $n=17)$. Application of isoprenaline reduced the sAHP by $73 \pm 4 \%(p<0.0001)$, and the AP-evoked calcium response during the sAHP increased from $55 \pm 5 \%$ of control before isoprenaline to $85 \pm 9 \%$ of control in the presence of isoprenaline $(p=0.003 ; n=11)$. These actions were partially reversed by application of the $\beta$-adrenergic receptor antagonist propranolol $(n=5)$ (Fig. 6E, F). drites is shown in Figure 7A--C. Our model predicts that somatic or proximal locations of the $\mathrm{SI}_{\mathrm{AHP}}$ would reduce the peak amplitude of the EPSP, whereas basal and uniform configurations would not (Fig. $7 A, B$ ). The model also predicts that the EPSP would decay faster during the sAHP regardless of where the conductance is located (Fig. $7 \mathrm{~A}, \mathrm{C}$ ). Conversely, hyperpolarizing current injections would be expected to increase the amplitude of the EPSP and slow its decay (Fig. 7A--C).

Finally, we tested the effect of $s I_{\mathrm{AHP}}$ distribution on the dendritic calcium response (Fig. $7 D--F$ ). We calculated the expected calcium influx into the dendrite $107 \mu \mathrm{m}$ from the soma during an AP. Placing the $s I_{\mathrm{AHP}}$ exclusively on the soma predicted a $2 \%$ reduction in AP-evoked calcium influx, whereas placing the sIAHP On the proximal dendritic tree predicted a $15 \%$ reduction in the dendritic calcium response, suggesting that the dendritic location of the $s I_{\mathrm{AHP}}$ may be necessary for the reduction of the AP-evoked calcium rise observed experimentally. Reduced calcium influx was also predicted for $s I_{\mathrm{AHP}}$ distributions encompassing the soma and proximal dendrite (15\% reduction) and uniformly throughout the neuron (15\% reduction). No reduction of the AP-evoked calcium response was forecast when the $s I_{\mathrm{AHP}}$ was restricted to the basal dendrites.

\section{Discussion}

The output of a neuron is determined by a combination of the spatiotemporal pattern of the synaptic inputs that it receives and the ion channels intrinsic to that neuron. Ion channels are often differentially distributed along the plasma membrane, and this distribution has important consequences for information processing. For example, A-type voltage-dependent $\mathrm{K}^{+}$channels and hyperpolarization-activated $\mathrm{HCN}$ channels are present at higher densities in dendrites in hippocampal pyramidal neurons (Hoffman et al., 1997; Magee, 1998) in which their activity shapes synaptic potentials and limits their integration (Hoffman et al., 1997). In many neurons, AP trains are followed by a prolonged 
afterhyperpolarization (sAHP) that results from activation of the calcium-dependent potassium current, $s I_{\mathrm{AHP}}$, and mediates spike-frequency adaptation. In this study, we investigated the distribution of the $s I_{\mathrm{AHP}}$ in BLA projection neurons. We found that, in these neurons, the $s I_{\mathrm{AHP}}$ appears to be distributed along the dendritic tree. Activation of this conductance shapes synaptic potentials and APs in the dendritic tree.

\section{Location of the $s I_{\mathrm{AHP}}$}

Although the $s I_{\mathrm{AHP}}$ is widely distributed throughout the CNS, the distribution of the underlying channels has only been studied in CA1 pyramidal neurons. These results have proven controversial, with some data suggesting that they are located primarily on the soma (Marrion and Tavalin, 1998; Lima and Marrion, 2007), whereas others indicate a predominantly dendritic distribution, with the channel being present either in the apical (Andreasen and Lambert, 1995; Sah and Bekkers, 1996; Lancaster et al., 2001) or basal (Bekkers, 2000) dendritic trees or in both compartments (Fernández de Sevilla et al., 2007). One confounding factor in the interpretation of some of these studies is a failure to distinguish between the contribution of apamin-sensitive SK channels and apamin-insensitive non-SK channels to the sAHP and the corresponding slow calciumactivated potassium current. The relative contributions of SK and non-SK channels to the sAHP is dependent on calcium buffering, intracellular calcium store content, and the presence of neuromodulatory transmitters (Velumian and Carlen, 1999; Power and Sah, 2008). The recording conditions of our study ensure that SK channels make little contribution to the $s \mathrm{AHP} / \mathrm{sI}_{\mathrm{AHP}}$ in $\mathrm{BLA}$ projection neurons (Fig. 1) (Power and Sah, 2008), and we can be confident that our data reflect the location and function of the apamin-insensitive $s I_{\mathrm{AHP}}$. Our voltage-shift data (Fig. 2) indicate that these channels are primarily located along the dendritic tree, electrotonically distant from the soma. In agreement with this, photolytic uncaging of calcium in the soma evoked only a fraction of the current that was evoked by a voltage step, despite having a comparable somatic calcium rise (Fig. 3). Although we cannot rule out the possibility that calcium entering via voltage-gated calcium channels in the membrane during voltage steps reaches high concentrations in microdomains in the vicinity of the channels, the $s I_{\mathrm{AHP}}$ is readily activated in CA1 pyramidal neurons by uncaging calcium with whole-field UV excitation, which releases calcium in both the soma and dendrites (Lancaster and Zucker, 1994; Sah and Clements, 1999). Addition-
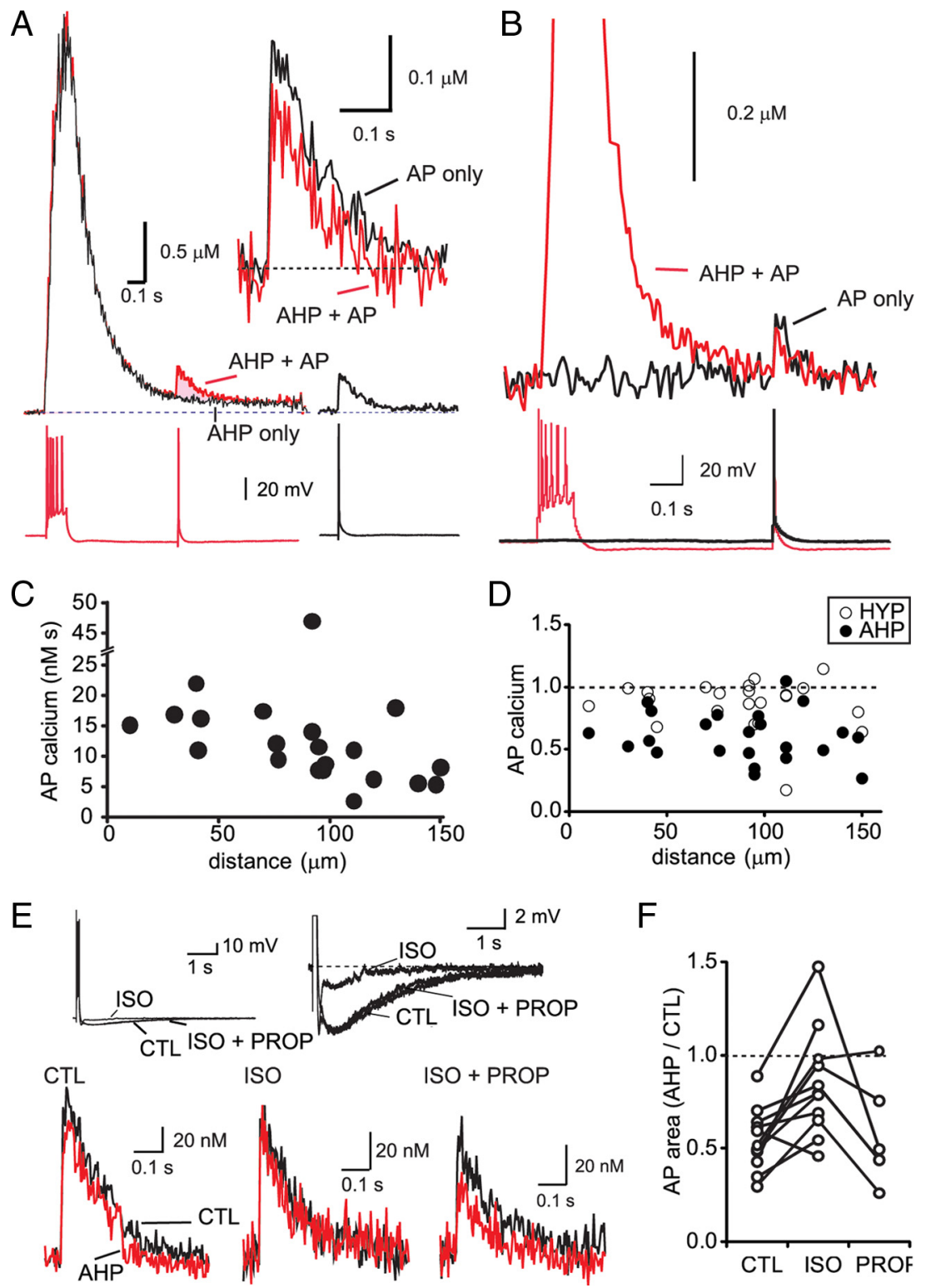

Figure 6. The SAHP reduces the dendritic AP-evoked calcium response. $A$, The AP-evoked calcium response is smaller during the SAHP. Top traces on the left show the calcium response in the dendrite ( $92 \mu \mathrm{m}$ from the soma) in response to an AP train (black trace; AHP only) and to an AP train followed by a single AP evoked 500 ms after the train (red trace; AHP + AP). The calcium response evoked by the AP trains (AHP only) was subtracted from the paired response (AHP + AP) to determine the calcium rise evoked by the AP during the AHP (shaded area). The voltage response at the soma is shown below the calcium response. Calcium rise evoked by a single AP under control conditions is shown on the right. Inset (top right) shows the AP-evoked calcium rise overlaid with the AP-evoked calcium rise during the SAHP. $B$, An example of a dendritic calcium response ( $140 \mu \mathrm{m}$ from the soma) in which there is little residual calcium from the AP train when the AP is evoked. In this instance, the peak response evoked by the control AP (black trace) is greater than the AP-evoked calcium rise during the SAHP (red trace). C, The AP-evoked calcium rise decreases with distance from the soma. The integrated area of the AP-evoked calcium rise in the dendrite is plotted against its distance from the soma. $D$, The AP-evoked dendritic calcium rise is attenuated during the SAHP but not during a hyperpolarizing somatic current injection that mimics the somatic hyperpolarization during the SAHP. The integrated area of the AP-evoked calcium rise during the sAHP (filled circles) and during a hyperpolarizing current injection (open circles) is plotted relative to control at various distances from the soma. $\boldsymbol{E}, \boldsymbol{F}$, Application of the $\beta$-adrenergic agonist isoprenaline reduces the SAHP and the attenuation of the APevoked calcium rise that follows the AP train. The somatic membrane potential is shown in response to a depolarizing current injection (100 ms) that evoked an AP train under control conditions (CTL) and after sequential application of isoprenaline (ISO) and the $\beta$-adrenergic receptor antagonist propranolol (PROP). The SAHP is shown on an expanded scale (right traces). The AP-evoked dendritic calcium rise before (blue) and during (red) the sAHP is shown under control conditions (bottom left traces), in the presence of isoprenaline (bottom middle traces), and in the presence of isoprenaline and propranolol (bottom right traces). $\boldsymbol{F}$, Summary data showing the relative area of the single AP-evoked calcium rise during the SAHP under control conditions (CTL), after application of isoprenaline (ISO), and after addition of propranolol (PROP). 
A
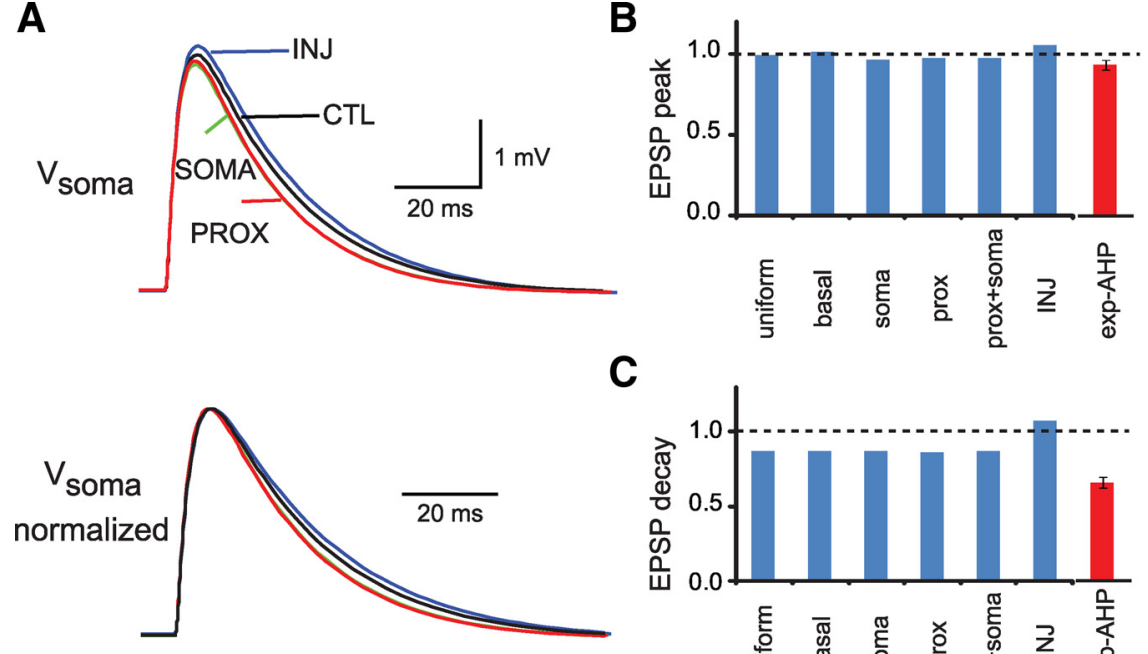

C

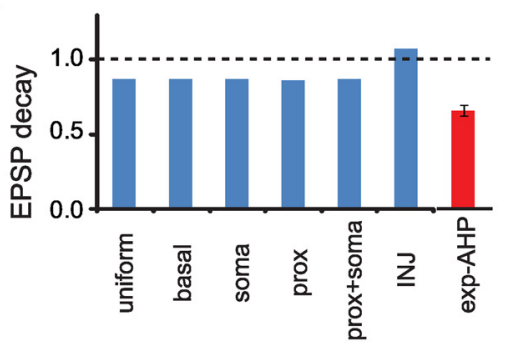

D
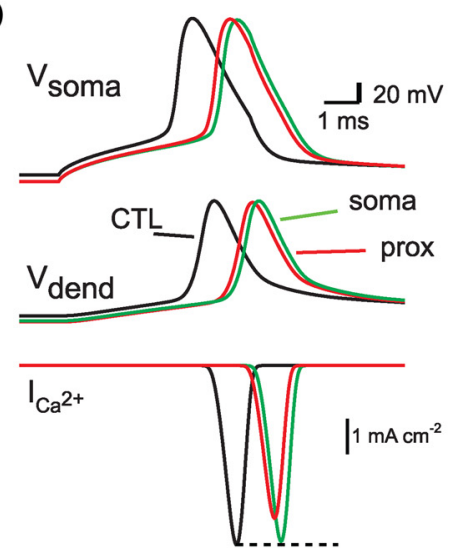

I

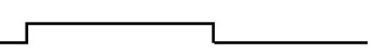

E

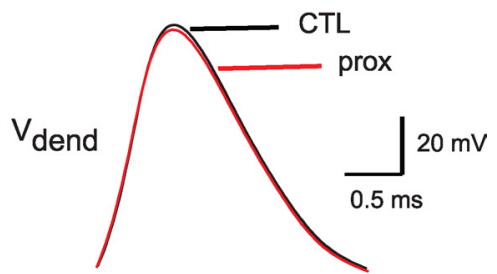

$\mathbf{F}$

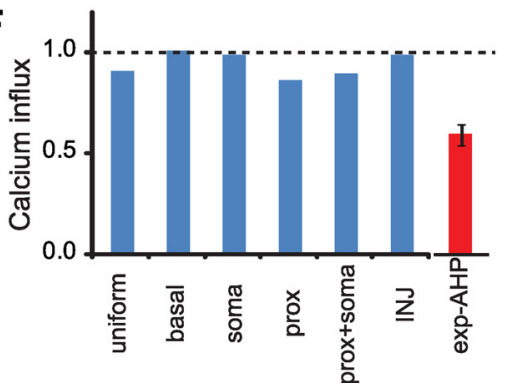

Figure 7. A computational model of a BLA neuron indicates that the $\mathrm{S}_{\mathrm{AHP}}$ channel location influences communication between the soma and dendrite. The effect of the SAHP on synaptic stimulation was modeled in $A-C$. Synaptic conductances were placed on the dendrite $105 \mu \mathrm{m}$ from the soma, and the resultant EPSPs were measured in the soma. EPSPs were evoked under resting conditions (CTL), during a $5 \mathrm{mV}$ SAHP, or during a somatic current injection (INJ) that hyperpolarized the soma by $5 \mathrm{mV}$. EPSPs evoked during the $S A H P$ were modeled with the $s I_{\text {AHP }}$ located on the soma (soma), the proximal dendrites (prox), both the soma and proximal dendrites (soma + prox), uniformly distributed throughout the neuron (uniform), or solely on the basal dendrites (basal). The bottom traces show the normalized EPSP to highlight the faster decay of the EPSP during the SAHP. $\boldsymbol{B}$, The modeled EPSP amplitudes, normalized to control EPSP amplitudes, are plotted (blue bars) for each $s l_{\text {AHP }}$ distribution and for a somatic current injection (INJ). The experimental results (exp-AHP) are plotted in red (mean \pm SEM). C, The normalized decay time constants are plotted for each condition. The model indicates that the EPSP would decay faster during the sAHP regardless of where the conductance is located. $\boldsymbol{D}-\boldsymbol{F}$, Attenuation of the AP-evoked dendritic calcium response during the $s A H P$ requires the $\left.s\right|_{A H P}$ to be located on the proximal dendritic tree. $\boldsymbol{D}$, The predicted APs evoked by somatic current injection under control conditions and during the SAHP with different distributions of the $s I_{A H P}$ are shown in the soma and dendrite (110 $\mu \mathrm{m}$ from the soma). The predicted dendritic calcium currents $\left(I_{\mathrm{Ca}^{2+}}\right)$ are shown below $V_{\text {dend }}$. $\boldsymbol{E}$, The AP waveforms in the dendrite are shown aligned to their onsets for each condition. Note the modest attenuation of the AP predicted for the proximal (prox) $s l_{\text {AHP }}$ distribution. $\boldsymbol{F}$, Restricting the ${ }_{\text {AHP }}$ to the soma (soma) has little effect on the AP-evoked calcium influx, whereas distributions that included the ${ }_{\text {AHP }}$ on the proximal apical dendritic tree (prox/soma + prox/uniform) attenuate the calcium response. The AP-evoked calcium influx is shown for each modeled condition in the panel below normalized to control. Experimental results (Fig. 6) showing the dendritic fluorescence signal (normalized to control) generated by APs evoked during the SAHP (exp-AHP) are shown in red.

ally, the current could be evoked by focal uncaging of calcium in the dendrites, indicating that these channels are present on the dendritic tree. It should be noted that the UV excitation is spatially restricted at the focal $x-y$ plane but not in the $z$-axis, and, as a consequence, calcium will also be uncaged to a lesser extent in dendrites located above or below the target region. Thus, current-evoked out-of-focus dendrites may have contributed to current evoked in our uncaging experiments. BLA projection neurons typically have five to six primary dendrites that radiate in several directions (McDonald, 1992; Faber et al., 2001). Even accounting for out-of-focus excitation, it is unlikely that we have stimulated $>20 \%$ of the proximal dendritic tree. Thus, the dendritic contribution of the current is expected to be five times that evoked by dendritic uncaging, easily compensating for the difference between the current evoked by the voltage step and that evoked by somatic uncaging of calcium. Together, these data indicate that a large portion of the channels, perhaps even most of the channels, are located on the dendritic tree. Using a computational model, we tested the impact of channel distributions on synaptic potentials and AP-evoked calcium response (Fig. 7). Results from this model indicate that, although the $s I_{\mathrm{AHP}}$ can hasten the decay of synaptic potentials, regardless of its cellular location, its dendritic distribution may be an important factor in the reduced AP-evoked calcium rise observed during the during the sAHP (Figs. 6, 7).

\section{Synaptic summation}

Because the $s I_{\mathrm{AHP}}$ is located on the dendritic tree, it is well positioned to shape synaptic potentials and control synaptic integration. We find that EPSPs decay faster (Fig. 4) and show less summation (Fig. 5) when evoked during the sAHP, but the effect of the sAHP on the EPSP amplitude was less consistent. Studies in hippocampal pyramidal neurons have consistently reported a reduction of the EPSP time course during the SAHP that results in reduced synaptic summation (Lancaster et al., 2001; Fernández de Sevilla et al., 2007). Some (Sah and Bekkers, 1996; Fernández de Sevilla et al., 2007; Fuenzalida et al., 2007), but not all (Lancaster et al., 2001), studies also find a reduction of the EPSP amplitude. In our initial observations (Fig. 3), we found a small but significant reduction of the EPSP amplitude; however, this reduction was not consistently observed (Fig. 4). It is possible that this difference reflects a differential distribution of the $s I_{\mathrm{AHP}}$ on the dendritic tree.

Activation of the sAHP is usually attributed to calcium influx during AP trains, when it contributes to spike-frequency adaptation. However, in CA1 pyramidal neurons, Lancaster et al. (2001) have shown that it can also be activated by subthreshold synaptic trains, consistent with a dendritic location of the channels. Such a synaptically activated hyperpolarization has been reported in BLA neurons in vivo (Lang and Paré, 1997), and we too noted a small hyperpolarization that followed synaptic trains under control conditions (Fig. 5). This hyperpolarization is not seen when synaptic trains are delivered during the $s A H P$, when $s I_{\mathrm{AHP}}$ channels are already activated. Although 
the identity of this hyperpolarization is not established, it is possible that it results from activation of the $s I_{\mathrm{AHP}}$ triggered by calcium influx from subthreshold activation of L-type voltage-dependent calcium channels (Magee et al., 1995; Power and Sah, 2005) or NMDA receptors. Synaptic activation of the sAHP may act to further reduce temporal summation by facilitating the $\mathrm{Mg}^{2+}$ reblock of activated NMDA receptors (Disterhoft et al., 2004; Fernández de Sevilla et al., 2007).

\section{Dendritic APs}

Electrical communication between the soma and dendrite is bidirectional. Whereas EPSPs propagate from the dendrites to the soma and axon, APs are initiated at the axon initial segment, propagate back into the dendritic tree (Stuart et al., 1997), and are critical for spike-timing-dependent synaptic plasticity (Markram et al., 1997). Backpropagation of APs is modulated by the density and distribution of ionic conductances present on the dendritic tree (Johnston et al., 1999; Sjostrom et al., 2008). Dendritic IPSPs have been shown to disrupt AP backpropagation through their shunting as well as their hyperpolarizing actions (Tsubokawa and Ross, 1996). We have shown that $\mathrm{s}_{\mathrm{AHP}}$ also modulates the AP in the dendrite, reducing calcium channel activation (Fig. 6). It is not clear whether the sAHP affects propagation of the AP or simply changes its waveform, resulting in a reduced calcium response. Because of its slow activation kinetics, the $s I_{\mathrm{AHP}}$ is not expected to have impact on a solitary AP or APs within brief trains; however, once activated, the $s I_{\mathrm{AHP}}$ would affect dendritic APs for several hundred milliseconds. Consistent with this notion, reduction of the SAHP by isoprenaline had no effect on the calcium rise evoked by a brief AP train (Fig. 1). However, when APs were evoked during the sAHP, $500 \mathrm{~ms}$ after the initial AP train, the resultant dendritic calcium rise was attenuated under control conditions but not when the sAHP was blocked (Fig. 6)

\section{$s I_{\mathrm{AHP}}$ and synaptic plasticity}

Our data show that the SAHP alters both synaptic integration and dendritic AP, but does it modulate synaptic plasticity? An abundance of data show that induction of LTP is facilitated when the $s I_{\mathrm{AHP}}$ is inhibited (Izquierdo and Medina, 1995; Sah and Bekkers, 1996; Disterhoft and Oh, 2006). In BLA projection neurons, the $s I_{\mathrm{AHP}}$ is suppressed by muscarinic (Washburn and Moises, 1992b; Power and Sah, 2008), $\beta$-adrenergic (Huang et al., 1996; Power and Sah, 2008), and metabotropic glutamatergic (Womble and Moises, 1994) receptor activation. Activation of these transmitter systems facilitates the induction of long-term potentiation (LTP) (Watanabe et al., 1995; Huang and Kandel, 1996; Ferry et al., 1997; Fendt and Schmid, 2002; Rodrigues et al., 2002; Pu et al., 2009). However, the actions of these transmitter systems are not limited to their suppression of the $\mathrm{s}_{\mathrm{AHP}}$, and thus such correlative data do not provide a causative link between the $s I_{\mathrm{AHP}}$ and synaptic plasticity. A recent study by Fuenzalida et al. (2007) has shown that induction of spike-timing-dependent LTP is disrupted during the sAHP. Our data suggest that the abbreviated EPSP and altered AP during the sAHP may act together to limit NMDA receptor activation and modulate NMDA-dependent synaptic plasticity.

\section{References}

Andreasen M, Lambert JD (1995) The excitability of CA1 pyramidal cell dendrites is modulated by a local $\mathrm{Ca}^{2+}$-dependent $\mathrm{K}^{+}$-conductance. Brain Res 698:193-203.

Bekkers JM (2000) Distribution of slow AHP channels on hippocampal CA1 pyramidal neurons. J Neurophysiol 83:1756-1759.

Callaway JC, Ross WN (1995) Frequency-dependent propagation of so- dium action potentials in dendrites of hippocampal CA1 pyramidal neurons. J Neurophysiol 74:1395-1403.

DeBock F, Kurz J, Azad SC, Parsons CG, Hapfelmeier G, Zieglgänsberger W, Rammes G (2003) Alpha2-adrenoreceptor activation inhibits LTP and LTD in the basolateral amygdala: involvement of Gi/o-protein-mediated modulation of $\mathrm{Ca}^{2+}$-channels and inwardly rectifying $\mathrm{K}^{+}$-channels in LTD. Eur J Neurosci 17:1411-1424.

Disterhoft JF, Oh MM (2006) Learning, aging and intrinsic neuronal plasticity. Trends Neurosci 29:587-599.

Disterhoft JF, Wu WW, Ohno M (2004) Biophysical alterations of hippocampal pyramidal neurons in learning, ageing and Alzheimer's disease. Ageing Res Rev 3:383-406.

Faber ES, Sah P (2002) Physiological role of calcium-activated potassium currents in the rat lateral amygdala. J Neurosci 22:1618-1628.

Faber ES, Callister RJ, Sah P (2001) Morphological and electrophysiological properties of principal neurons in the rat lateral amygdala in vitro. J Neurophysiol 85:714-723.

Faber ES, Delaney AJ, Power JM, Sedlak PL, Crane JW, Sah P (2008) Modulation of SK channel trafficking by beta adrenoceptors enhances excitatory synaptic transmission and plasticity in the amygdala. J Neurosci 28:10803-10813.

Fendt M, Schmid S (2002) Metabotropic glutamate receptors are involved in amygdaloid plasticity. Eur J Neurosci 15:1535-1541.

Fernández de Sevilla D, Fuenzalida M, Porto Pazos AB, Buño W (2007) Selective shunting of the NMDA EPSP component by the slow afterhyperpolarization in rat CA1 pyramidal neurons. J Neurophysiol 97:3242-3255.

Ferry B, Magistretti PJ, Pralong E (1997) Noradrenaline modulates glutamate-mediated neurotransmission in the rat basolateral amygdala in vitro. Eur J Neurosci 9:1356-1364.

Foehring RC, Scroggs RS (1994) Multiple high-threshold calcium currents in acutely isolated rat amygdaloid pyramidal cells. J Neurophysiol 71:433-436.

Fuenzalida M, Fernandez de Sevilla D, Buño W (2007) Changes of the EPSP waveform regulate the temporal window for spike-timing-dependent plasticity. J Neurosci 27:11940-11948.

Gasparini S, Migliore M, Magee JC (2004) On the initiation and propagation of dendritic spikes in CA1 pyramidal neurons. J Neurosci 24:11046-11056.

Harris KM, Stevens JK (1989) Dendritic spines of CA 1 pyramidal cells in the rat hippocampus: serial electron microscopy with reference to their biophysical characteristics. J Neurosci 9:2982-2997.

Häusser M, Roth A (1997) Estimating the time course of the excitatory synaptic conductance in neocortical pyramidal cells using a novel voltage jump method. J Neurosci 17:7606-7625.

Hille B (2001) Ion channels of excitable membranes. Sunderland, MA: Sinauer Associates.

Hines ML, Carnevale NT (1997) The NEURON simulation environment. Neural Comput 9:1179-1209.

Hoffman DA, Magee JC, Colbert CM, Johnston D (1997) $\mathrm{K}^{+}$channel regulation of signal propagation in dendrites of hippocampal pyramidal neurons. Nature 387:869-875.

Huang CC, Hsu KS, Gean PW (1996) Isoproterenol potentiates synaptic transmission primarily by enhancing presynaptic calcium influx via $\mathrm{P}$ - and/or Q-type calcium channels in the rat amygdala. J Neurosci 16:1026-1033.

Huang YY, Kandel ER (1996) Modulation of both the early and the late phase of mossy fiber LTP by the activation of beta-adrenergic receptors. Neuron 16:611-617.

Isaacson JS, Walmsley B (1995) Receptors underlying excitatory synaptic transmission in slices of the rat anteroventral cochlear nucleus. J Neurophysiol 73:964-973.

Izquierdo I, Medina JH (1995) Correlation between the pharmacology of long-term potentiation and the pharmacology of memory. Neurobiol Learn Mem 63:19-32.

Jack J, Noble D, Tsien RY, eds (1983) Electric current flow in excitable cells. Oxford: Clarendon.

Jahr CE, Stevens CF (1990) A quantitative description of NMDA receptorchannel kinetic behavior. J Neurosci 10:1830-1837.

Jahromi BS, Zhang L, Carlen PL, Pennefather P (1999) Differential timecourse of slow afterhyperpolarizations and associated $\mathrm{Ca}^{2+}$ transients in rat CA1 pyramidal neurons: further dissociation by $\mathrm{Ca}^{2+}$ buffer. Neuroscience 88:719-726.

Johnston D, Hoffman DA, Colbert CM, Magee JC (1999) Regulation of back-propagating action potentials in hippocampal neurons. Curr Opin Neurobiol 9:288-292. 
Knöpfel T, Vranesic I, Gähwiler BH, Brown DA (1990) Muscarinic and beta-adrenergic depression of the slow $\mathrm{Ca}^{2+}$-activated potassium conductance in hippocampal CA3 pyramidal cells is not mediated by a reduction of depolarization-induced cytosolic $\mathrm{Ca}^{2+}$ transients. Proc Natl Acad Sci U S A 87:4083-4087.

Lancaster B, Zucker RS (1994) Photolytic manipulation of $\mathrm{Ca}^{2+}$ and the time course of slow, $\mathrm{Ca}^{2+}$-activated $\mathrm{K}^{+}$current in rat hippocampal neurones. J Physiol 475:229-239.

Lancaster B, Hu H, Ramakers GM, Storm JF (2001) Interaction between synaptic excitation and slow afterhyperpolarization current in rat hippocampal pyramidal cells. J Physiol 536:809-823.

Lang EJ, Paré D (1997) Synaptic and synaptically activated intrinsic conductances underlie inhibitory potentials in cat lateral amygdaloid projection neurons in vivo. J Neurophysiol 77:353-363.

Lima PA, Marrion NV (2007) Mechanisms underlying activation of the slow AHP in rat hippocampal neurons. Brain Res 1150:74-82.

Lopez de Armentia M, Sah P (2003) Development and subunit composition of synaptic NMDA receptors in the amygdala: NR2B synapses in the adult central amygdala. J Neurosci 23:6876-6883.

Madison DV, Nicoll RA (1982) Noradrenaline blocks accommodation of pyramidal cell discharge in the hippocampus. Nature 299:636-638.

Magee JC (1998) Dendritic hyperpolarization-activated currents modify the integrative properties of hippocampal CA1 pyramidal neurons. J Neurosci 18:7613-7624.

Magee JC (1999) Dendritic Ih normalizes temporal summation in hippocampal CA1 neurons. Nat Neurosci 2:848.

Magee JC, Christofi G, Miyakawa H, Christie B, Lasser-Ross N, Johnston D (1995) Subthreshold synaptic activation of voltage-gated $\mathrm{Ca}^{2+}$ channels mediates a localized $\mathrm{Ca}^{2+}$ influx into the dendrites of hippocampal pyramidal neurons. J Neurophysiol 74:1335-1342.

Magee J, Hoffman D, Colbert C, Johnston D (1998) Electrical and calcium signaling in dendrites of hippocampal pyramidal neurons. Annu Rev Physiol 60:327-346.

Markram H, Helm PJ, Sakmann B (1995) Dendritic calcium transients evoked by single back-propagating action potentials in rat neocortical pyramidal neurons. J Physiol 485:1-20.

Markram H, Lübke J, Frotscher M, Sakmann B (1997) Regulation of synaptic efficacy by coincidence of postsynaptic APs and EPSPs. Science 275:213-215.

Marrion NV, Tavalin SJ (1998) Selective activation of $\mathrm{Ca}^{2+}$-activated $\mathrm{K}^{+}$ channels by co-localized $\mathrm{Ca}^{2+}$ channels in hippocampal neurons. Nature 395:900-905.

McDonald AJ (1992) Projection neurons of the basolateral amygdala: a correlative Golgi and retrograde tract tracing study. Brain Res Bull 28:179-185.

Migliore M, Cook EP, Jaffe DB, Turner DA, Johnston D (1995) Computer simulations of morphologically reconstructed CA3 hippocampal neurons. J Neurophysiol 73:1157-1168.

Müller W, Connor JA (1991) Dendritic spines as individual neuronal compartments for synaptic $\mathrm{Ca}^{2+}$ responses. Nature 354:73-76.

Nicoll RA (1988) The coupling of neurotransmitter receptors to ion channels in the brain. Science 241:545-551.

Nishijo H, Ono T, Nishino H (1988) Single neuron responses in amygdala of alert monkey during complex sensory stimulation with affective significance. J Neurosci 8:3570-3583.

O'Keefe J, Bouma H (1969) Complex sensory properties of certain amygdala units in the freely moving cat. Exp Neurol 23:384-398.

Paré D, Gaudreau H (1996) Projection cells and interneurons of the lateral and basolateral amygdala: distinct firing patterns and differential relation to theta and delta rhythms in conscious cats. J Neurosci 16:3334-3350.

Power JM, Sah P (2002) Nuclear calcium signaling evoked by cholinergic stimulation in hippocampal CA1 pyramidal neurons. J Neurosci 22:3454-3462.

Power JM, Sah P (2005) Intracellular calcium store filling by an L-type calcium current in the basolateral amygdala at subthreshold membrane potentials. J Physiol 562:439-453.

Power JM, Sah P (2007) Distribution of IP3-mediated calcium responses in basolateral amygdala neurons and their role in nuclear signalling. J Physiol 580:835-857.

Power JM, Sah P (2008) Competition between calcium-activated $\mathrm{K}^{+}$chan- nels determines cholinergic action on firing properties of basolateral amygdala projection neurons. J Neurosci 28:3209-3220.

Pu Z, Krugers HJ, Joëls M (2009) Beta-adrenergic facilitation of synaptic plasticity in the rat basolateral amygdala in vitro is gradually reversed by corticosterone. Learn Mem 16:155-160.

Rainnie DG, Shinnick-Gallagher P (1992) Trans-ACPD and L-APB presynaptically inhibit excitatory glutamatergic transmission in the basolateral amygdala (BLA). Neurosci Lett 139:87-91.

Rodrigues SM, Bauer EP, Farb CR, Schafe GE, LeDoux JE (2002) The group I metabotropic glutamate receptor mGluR5 is required for fear memory formation and long-term potentiation in the lateral amygdala. J Neurosci 22:5219-5229.

Sah P, Bekkers JM (1996) Apical dendritic location of slow afterhyperpolarization current in hippocampal pyramidal neurons: implications for the integration of long-term potentiation. J Neurosci 16:4537-4542.

Sah P, Clements JD (1999) Photolytic manipulation of $\left[\mathrm{Ca}^{2+}\right]_{\mathrm{i}}$ reveals slow kinetics of potassium channels underlying the afterhyperpolarization in hippocampal pyramidal neurons. J Neurosci 19:3657-3664.

Sah P, Faber ES (2002) Channels underlying neuronal calcium-activated potassium currents. Prog Neurobiol 66:345-353.

Sah P, Faber ES, Lopez De Armentia M, Power J (2003) The amygdaloid complex: anatomy and physiology. Physiol Rev 83:803-834.

Schiller J, Helmchen F, Sakmann B (1995) Spatial profile of dendritic calcium transients evoked by action potentials in rat neocortical pyramidal neurones. J Physiol 487:583-600.

Sjöström PJ, Rancz EA, Roth A, Häusser M (2008) Dendritic excitability and synaptic plasticity. Physiol Rev 88:769-840.

Spruston N, Jaffe DB, Johnston D (1994) Dendritic attenuation of synaptic potentials and currents: the role of passive membrane properties. Trends Neurosci 17:161-166.

Stuart G, Spruston N, Sakmann B, Häusser M (1997) Action potential initiation and backpropagation in neurons of the mammalian CNS. Trends Neurosci 20:125-131.

Tsubokawa H, Ross WN (1996) IPSPs modulate spike backpropagation and associated $\left[\mathrm{Ca}^{2+}\right]_{\mathrm{i}}$ changes in the dendrites of hippocampal CA1 pyramidal neurons. J Neurophysiol 76:2896-2906.

Tzingounis AV, Nicoll RA (2008) Contribution of KCNQ2 and KCNQ3 to the medium and slow afterhyperpolarization currents. Proc Natl Acad Sci U S A 105:19974-19979.

Tzingounis AV, Heidenreich M, Kharkovets T, Spitzmaul G, Jensen HS, Nicoll RA, Jentsch TJ (2010) The KCNQ5 potassium channel mediates a component of the afterhyperpolarization current in mouse hippocampus. Proc Natl Acad Sci U S A 107:10232-10237.

Velumian AA, Carlen PL (1999) Differential control of three afterhyperpolarizations in rat hippocampal neurones by intracellular calcium buffering. J Physiol 517:201-216.

Vicini S, Wang JF, Li JH, Zhu WJ, Wang YH, Luo JH, Wolfe BB, Grayson DR (1998) Functional and pharmacological differences between recombinant N-methyl-D-aspartate receptors. J Neurophysiol 79:555-566.

Washburn MS, Moises HC (1992a) Electrophysiological and morphological properties of rat basolateral amygdaloid neurons in vitro. J Neurosci 12:4066-4079.

Washburn MS, Moises HC (1992b) Muscarinic responses of rat basolateral amygdaloid neurons recorded in vitro. J Physiol 449:121-154.

Watanabe Y, Ikegaya Y, Saito H, Abe K (1995) Roles of GABAA, NMDA and muscarinic receptors in induction of long-term potentiation in the medial and lateral amygdala in vitro. Neurosci Res 21:317-322.

Waters J, Schaefer A, Sakmann B (2005) Backpropagating action potentials in neurones: measurement, mechanisms and potential functions. Prog Biophys Mol Biol 87:145-170.

Womble MD, Moises HC (1993) Muscarinic modulation of conductances underlying the afterhyperpolarization in neurons of the rat basolateral amygdala. Brain Res 621:87-96.

Womble MD, Moises HC (1994) Metabotropic glutamate receptor agonist ACPD inhibits some, but not all, muscarinic-sensitive $\mathrm{K}^{+}$conductances in basolateral amygdaloid neurons. Synapse 17:69-75.

Yasuda R, Nimchinsky EA, Scheuss V, Pologruto TA, Oertner TG, Sabatini BL, Svoboda K (2004) Imaging calcium concentration dynamics in small neuronal compartments. Sci STKE 2004:p15. 